\title{
Are there shared neural correlates between dyslexia and ADHD? A meta-analysis of voxel-based morphometry studies
}

\author{
Lauren M. McGrath ${ }^{1 *}$ (iD and Catherine J. Stoodley ${ }^{2}$
}

\begin{abstract}
Background: Dyslexia and Attention-deficit/hyperactivity disorder (ADHD) are highly comorbid neurodevelopmental disorders (estimates of $25-40 \%$ bidirectional comorbidity). Previous work has identified strong genetic and cognitive overlap between the disorders, but neural overlap is relatively unexplored. This study is a systematic meta-analysis of existing voxel-based morphometry studies to determine whether there is any overlap in the gray matter correlates of both disorders.

Methods: We conducted anatomic likelihood estimate (ALE) meta-analyses of voxel-based morphometry studies in which individuals with dyslexia (15 studies; 417 cases, 416 controls) or ADHD (22 studies; 898 cases, 763 controls) were compared to typically developing controls. We generated ALE maps for dyslexia vs. controls and ADHD vs. controls using more conservative $(p<.001, k=50)$ and more lenient $(p<.005, k=50)$ thresholds. To determine the overlap of gray matter correlates of dyslexia and ADHD, we examined the statistical conjunction between the ALE maps for dyslexia vs. controls and ADHD vs. controls (false discovery rate [FDR] $p<.05, k=50,5000$ permutations).

Results: Results showed largely distinct gray matter differences associated with dyslexia and ADHD. There was no evidence of statistically significant gray matter overlap at our conservative threshold, and only one region of overlap in the right caudate at our more lenient threshold. Reduced gray matter in the right caudate may be relevant to shared cognitive correlates in executive functioning and/or procedural learning. The more general finding of largely distinct regional differences in gray matter between dyslexia and ADHD suggests that other neuroimaging modalities may be more sensitive to overlapping neural correlates, and that current neuroimaging recruitment approaches may be hindering progress toward uncovering neural systems associated with comorbidity.

Conclusions: The current study is the first to meta-analyze overlap between gray matter differences in dyslexia and $A D H D$, which is a critical step toward constructing a multi-level understanding of this comorbidity that spans the genetic, neural, and cognitive levels of analysis.
\end{abstract}

Keywords: Voxel-based morphometry, Meta-analysis, Dyslexia, Attention-deficit/hyperactivity disorder, Caudate

\section{Background}

Dyslexia (also known as DSM-5 Specific Learning Disorder with Impairment in Reading) and Attention-deficit/hyperactivity disorder (ADHD) are both prevalent developmental disorders $(5-10 \%)$ with a high, bidirectional comorbidity rate $(25-40 \%)[1,2]$. One theoretical advancement that is guiding the study of comorbidity is the shift from single

\footnotetext{
* Correspondence: lauren.mcgrath@du.edu

'Department of Psychology, University of Denver, Frontier Hall, 2155 S. Race St., Denver, CO 80208, USA

Full list of author information is available at the end of the article
}

deficit to multiple deficit models in developmental neuropsychology [3]. The multiple deficit model stipulates that there are multiple, probabilistic predictors of developmental disorders across levels of analysis and that comorbidity arises because of risk factors that are shared by disorders [3]. This multiple deficit framework has been useful for advancing the science of comorbidity, particularly for integrating the genetic, neural, and cognitive levels of analysis to explain comorbidity. There is strong evidence for shared genetic and neuropsychological risk factors that contribute to the dyslexia-ADHD comorbidity; what is missing are the

(c) The Author(s). 2019 Open Access This article is distributed under the terms of the Creative Commons Attribution 4.0 International License (http://creativecommons.org/licenses/by/4.0/), which permits unrestricted use, distribution, and 
potential overlapping neural risk factors that can connect these levels of analysis. This gap at the neural level is preventing the specification of a fully integrated model of the dyslexia-ADHD comorbidity that spans multiple levels of analysis.

At the genetic level of analysis, the bulk of the evidence supports the correlated liabilities model of comorbidity between dyslexia and ADHD [4], which posits that shared genetic influences cause both disorders to manifest in the same child more often than expected by chance. Evidence in support of the correlated liabilities model is derived from multivariate behavioral genetic studies of twins, which can establish the extent to which genetic influences on one disorder overlap with genetic influences on the second disorder [5]. One way to quantify the extent of the genetic overlap is with a statistic called the genetic correlation, which ranges from 0 (genetic influences on one trait are not associated with the second trait) to 1 (all of the genetic influences on one trait also influence the second trait) [5]. One way to interpret the genetic correlation is that it expresses the probability that a gene associated with one trait will also be associated with the second trait [6]. Estimates of the genetic correlation between dyslexia and ADHD are quite strong, in the range of .50 and extending up to .70 in some studies [7].

At the neuropsychological level of analysis, there is also evidence for shared risk factors, most notably deficits in processing speed [8-18] and aspects of executive functioning, including working memory [17, 19-24], inhibition $[17,25,26]$, and sustained attention $[17,26]$.

In comparison to the progress in understanding the comorbidity of dyslexia and ADHD at the genetic and neuropsychological levels of analysis, there is a striking gap at the neural level of analysis. For example, there are only a handful of structural neuroimaging studies that have directly examined the comorbid dyslexia+ADHD group [27-31]. The bulk of neuroimaging designs either (a) recruit "pure" groups without comorbidities or (b) compare separate groups based on comorbidity status (i.e., dyslexia, ADHD, dyslexia+ADHD). While both of these strategies are useful for specific research questions, neither directly addresses why the disorders co-occur in the first place. In fact, both designs address the question of what distinguishes one disorder from another, rather than identifying transdiagnostic regions where they have shared features.

Such a transdiagnostic approach has been rare in developmental neuroimaging samples to date (for exceptions see $[32,33])$, but there is a notable meta-analytic study in the adult psychiatric neuroimaging literature that can provide a guiding framework. Goodkind et al. [34] analyzed structural neuroimaging studies of clinical disorders vs. controls. The clinical disorders covered a broad range (i.e., schizophrenia, bipolar disorder, major depressive disorder, substance use disorders, obsessivecompulsive disorders, and anxiety disorders). The authors meta-analyzed the existing voxel-based morphometry (VBM) studies of each disorder and then conducted a conjunction analysis to identify regions that were common across disorders. Results pointed to the dorsal anterior cingulate cortex and the bilateral insula as regions with less gray matter across clinical disorders compared to controls. Both of these regions have been associated with executive dysfunction, which is consistent with cognitive studies reporting that executive dysfunction is often a cross-cutting cognitive phenotype across a diverse range of psychiatric and neurodevelopmental disorders [34-37], including dyslexia and ADHD. More generally, these findings illustrate the potential to identify transdiagnostic correlates even in samples that were not initially recruited to directly study comorbidity.

In the dyslexia and ADHD literature, there is one meta-analysis completed by one of the authors (CJS) that directly tested for brain regions associated with both dyslexia and ADHD, but it focused exclusively on the cerebellum [38]. This study was a meta-analysis of cerebellar VBM studies in dyslexia and ADHD. There was no overlap between cerebellar clusters associated with dyslexia and ADHD, but there was potential functional overlap in the ventral attention system because clusters identified in the cerebellum for both disorders were implicated in this attentional network [38].

Given the sparse literature on shared neural correlates between dyslexia and ADHD, it is useful to speculate about neural systems that might be implicated in both disorders. For dyslexia, the most commonly implicated neural correlates involve a reading network that comprises left occipitotemporal regions, left temporoparietal regions, and the left inferior frontal gyrus [39]. In ADHD, the most frequently implicated regions include the prefrontal cortex and striatum [40-42]. While there are not obvious points of overlap in the canonical regions implicated in both disorders, it remains possible that there are regions of overlap that have received less attention because they are not part of these canonical regions.

As a result, in the current study, we utilize a quantitative meta-analytic approach to systematically test for common neural correlates. Specifically, we examine differences in gray matter volume identified via voxel-based morphometry (VBM) methods [43, 44]. VBM is the most widely-used automated technique for the analysis of structural brain images. While differences in functional activation and structural and functional connectivity are also implicated in dyslexia and ADHD, we chose to focus on gray matter correlates for this initial study because the VBM literature is robust in both dyslexia and ADHD ( $N=15$ dyslexia studies, $N=22$ ADHD studies). 
The meta-analytic approach allows us to be inclusive of studies across the lifespan in order to maximize sample size, while also examining heterogeneity across age. Importantly, our analytic strategy is designed to identify transdiagnostic gray matter correlates as compared to the prevailing neuroimaging designs, which focus on distinctions between the disorders. The overall goal of this metaanalysis is to identify overlap in brain regions associated with dyslexia or ADHD in VBM studies of these disorders. Such areas of overlap will advance our understanding of the dyslexia/ADHD comorbidity at the neural level, which is a critical gap in the literature given important advances at both the etiological and neuropsychological levels of analysis in understanding this comorbidity.

\section{Methods}

In reporting the results of this systematic meta-analysis, we have followed the guidelines proposed by Müller et al. [45] for reporting neuroimaging meta-analyses, which are aligned with recommendations from PRISMA (Preferred Reporting Items for Systematic Reviews and Meta-analyses) [46] (see Checklist in Additional file 1: Table S1).

\section{Literature search}

Pubmed (http://www.ncbi.nlm.nih.gov/pubmed) was used as a primary search database with follow-up searches completed using Google scholar (https://scholar.google. $\mathrm{com} /$ ). The literature search was completed in April 2018. For the PubMed searches, we used curated medical subject headings for dyslexia ("dyslexia") and ADHD ("Attention Deficit Disorder with Hyperactivity") as well as permutations of relevant keywords (e.g., dyslexia, reading disability, reading disorder, ADHD, attention-deficit). To narrow the vast neuroimaging literatures to those studies using VBM methods, we used permutations of the phrases "voxel-based" and "gray matter." The VBM method was first published in 2000, so we limited our search to publications between 1 January 1999 and 30 April 2018. The PubMed search syntax for dyslexia was as follows: (Dyslexia [MeSH] OR dyslex* OR reading disab* OR reading disorder") AND ("voxel-based" OR "voxel based" OR VBM OR "gray matter" OR "grey matter") AND ("1999/01/ 01"[Date - Publication]"2018/04/30"[Date - Publication]) AND English[Language]. The PubMed search syntax for ADHD was as follows: (Attention Deficit Disorder with Hyperactivity [MeSH] OR ADHD OR attention"deficit) AND ("voxel-based" OR "voxel based" OR VBM OR "gray matter" OR "gray matter") AND ("1999/01/01"[Date Publication]: "2018/04/30"[Date - Publication]) AND English[Language]. To ensure that we had identified all relevant studies, we also cross-referenced our searches with previous VBM meta-analyses for dyslexia [47-49] and ADHD [32, 40, 50, 51]. Additional searches with the same keywords in Google scholar did not turn up additional papers that met inclusion criteria beyond those identified through PubMed and existing meta-analyses.

In order to be included, studies were required to use whole-brain voxel-based morphometry (VBM) methods and to compare the clinical group with typically developing age-matched comparison groups. Methodological exclusion criteria included studies that reported non-VBM or only region-of-interest analyses of structural MRI data, studies in which results were not reported in standard coordinate space (Montreal Neurological Institute [MNI] [53] or Talairach and Tournoux [54]), studies reporting incomplete coverage of the whole brain, and studies that investigated clinical populations without reporting comparison data with a typically developing control group. We excluded studies whose primary focus was to investigate a comorbid disorder (e.g., individuals with ADHD and Autism Spectrum Disorder) and studies focused on quantitative dimensions of reading or ADHD symptomatology without clearly identified dyslexic or ADHD groups. We excluded studies of prereaders at risk for dyslexia because our interest was in cases with confirmed dyslexia, and we excluded one study of preschoolers with ADHD because it was the only study in this early age range. We excluded two consortium studies, one for ADHD [55] and one for dyslexia [47], because they likely included participant overlap with existing studies (see Fig. 1 for a flow chart of screening procedures).

Nine studies that otherwise met criteria were not included in the meta-analysis because they did not report any group differences (two for dyslexia, $[47,56]$; seven for ADHD, [57-63]). These null results do not contribute to the overall meta-analysis because the anatomic likelihood estimate (ALE) method tests for spatial convergence of foci across studies against the null hypothesis of random spatial convergence. As such, null results do not impact our coordinate-based meta-analysis in the same way as a traditional behavioral meta-analysis.

Table 1 lists the 37 studies that met inclusion criteria, with 22 investigating ADHD and 15 investigating dyslexia (see Additional file 2: Table S2 for expanded description). In the ADHD studies, 24 separate group contrasts were entered into the meta-analysis, and 18 different group contrasts were included for the studies investigating dyslexia. These numbers are consistent with guidelines for the number of studies needed for sufficient power $(N=$ 17-20) in neuroimaging meta-analyses [101]. We opted not to restrict studies further by sample size requirements or study-specific statistical correction thresholds in order to be maximally inclusive of the existing VBM literature.

\section{Sample overlap}

To examine sample overlap, we identified author overlap in papers for dyslexia or ADHD. For papers where there 


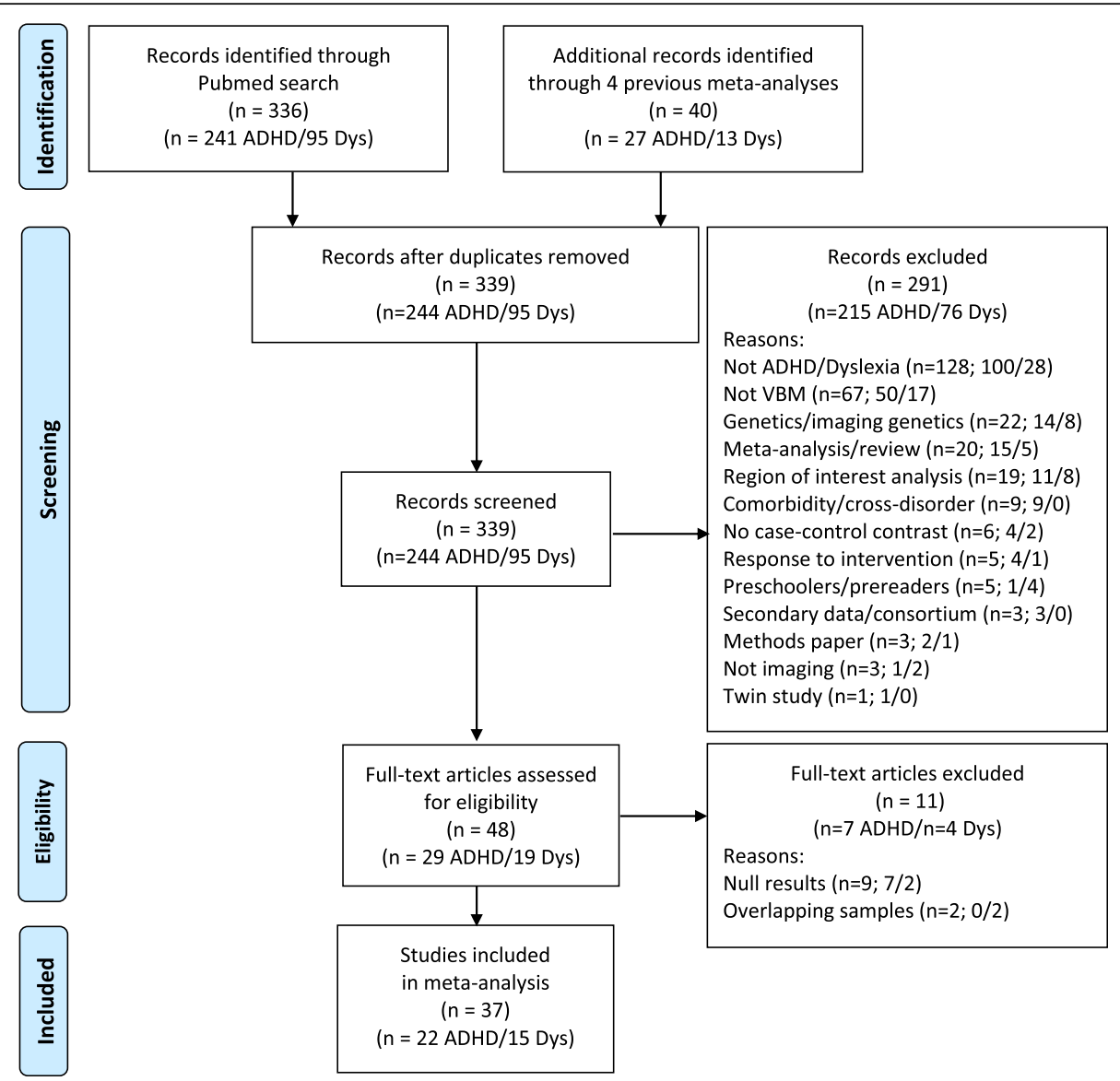

Fig. 1 PRISMA flow chart of literature search and screening for ADHD and dyslexia voxel-based morphometry case-control studies. From [46]. For more information, visit www.prisma-statement.org

were overlapping authors, we examined the methods section for indications of sample overlap and for distinguishing features such as age range, recruitment source, or image acquisition parameters. The methods section of Jednoróg et al. [91] indicated partial overlap with a previous paper by Jednoróg et al. [102] which was removed from the analysis. In cases of ambiguity, we reached out to authors for clarification. Based on this correspondence, we removed Krafnick et al. [103] because of partial overlap with Evans et al. [104]. At the time of submission, there was an unresolved question of partial overlap between Brieber et al. [67] $(N=15$ children with ADHD) and Johnston et al. [71] ( $N=34$ children with ADHD). There was no indication of sample overlap in the methods and a large time span between publications, so we included both studies in the final meta-analysis. However, out of an excess of caution, we re-ran the main conjunction analysis dropping the Brieber et al. study and confirmed the primary result was stable, only showing trivial changes in cluster size and ALE values (right caudate conjunction, $k=104$ vs. 112 , ALE $8.36 \times 10^{-3}$ vs. $8.48 \times 10^{-3}$, MNI coordinates $x=10, y=14$, and $z=8$ ).

\section{Comorbid disorders in included studies}

In ADHD, the most commonly reported comorbid disorders were anxiety disorders, oppositional defiant disorder, conduct disorder, and obsessive-compulsive disorder (Additional file 2: Table S2). Most ADHD studies (16 of 22, 73\%) did not comment on dyslexia or learning disabilities in their exclusion criteria. Only three studies explicitly reported comorbidities with learning disabilities/dyslexia in their participants: 1 child with dyslexia of 18 ADHD cases [80], 1 child with dyslexia of 34 cases [71], and 5 children with learning disabilities of 57 ADHD cases [85].

The majority of dyslexia studies excluded all psychiatric disorders, with 7 of 15 (47\%) specifically noting that participants with ADHD were excluded (Table 1). It is not clear if all authors considered ADHD in their screening of psychiatric disorders, especially since some studies noted only "severe psychiatric disorders." None of the studies reported cases with comorbid ADHD in their samples.

These patterns indicate that the neuroimaging literature has generally taken a "pure cases" approach to recruitment. 
Table 1 Characteristics of studies included in the meta-analysis

\begin{tabular}{|c|c|c|c|c|c|c|c|c|c|c|}
\hline \multirow[t]{2}{*}{ Study (reference) } & \multirow{2}{*}{$\begin{array}{l}\text { Total } \\
N\end{array}$} & \multirow{2}{*}{$\begin{array}{l}\text { Age } \\
\text { group } \\
\text { analysis }\end{array}$} & \multicolumn{3}{|c|}{ Clinical group } & \multicolumn{3}{|c|}{ Control group } & \multirow{2}{*}{$\begin{array}{l}\text { Included } \\
\text { in brain } \\
\text { volume } \\
\text { corrected } \\
\text { analysis }\end{array}$} & \multirow{2}{*}{$\begin{array}{l}\text { Comorbidity } \\
\text { with dyslexia } \\
\text { or ADHD noted in } \\
\text { exclusion criteria }\end{array}$} \\
\hline & & & $\bar{N}$ & $\begin{array}{l}\% \\
\text { male }\end{array}$ & $\begin{array}{l}\text { Mean age } \\
\text { (years) }\end{array}$ & $N$ & $\begin{array}{l}\% \\
\text { male }\end{array}$ & Mean age (years) & & \\
\hline \multicolumn{11}{|l|}{ ADHD } \\
\hline Ahrendts et al. [64] & 62 & Adult & 31 & 65 & 31.2 & 31 & 65 & 31.5 & Yes & $\begin{array}{l}\text { No learning } \\
\text { disability }\end{array}$ \\
\hline Bonath et al. [65] & 36 & - & 18 & 100 & 13.6 & 18 & 100 & 14.1 & Yes & - \\
\hline Bralten et al. [66] & 503 & - & 307 & 68 & 17.1 & 196 & 51 & 16.7 & No & $\begin{array}{l}\text { No learning } \\
\text { disability }\end{array}$ \\
\hline Brieber et al. [67] & 30 & - & 15 & 100 & 13.1 & 15 & 100 & 13.3 & Yes & - \\
\hline Carmona et al. [68] & 50 & Child & 25 & 84 & 10.8 & 25 & 84 & 11.2 & Yes & - \\
\hline He et al. [69] & 72 & Child & 37 & 100 & 9.9 & 35 & 100 & 10.7 & Yes & - \\
\hline lannaccone et al. [70] & 40 & - & 20 & 61 & 14.5 & 20 & 50 & 14.8 & Yes & - \\
\hline Johnston et al. [71] & 68 & - & 34 & 100 & 12.5 & 34 & 100 & 13.2 & No & - \\
\hline $\begin{array}{l}\text { Kappel et al. (adults) } \\
{[72]}\end{array}$ & 36 & Adult & 16 & 94 & 23.5 & 20 & 100 & 23.7 & No & - \\
\hline $\begin{array}{l}\text { Kappel et al. } \\
\text { (children) [72] }\end{array}$ & 24 & Child & 14 & 71 & 9.8 & 10 & 80 & 11.0 & No & - \\
\hline Kaya et al. [73] & 37 & Child & 19 & 71 & 10.3 & 18 & 67 & 10.2 & No & - \\
\hline Kobel et al. [74] & 26 & Child & 14 & 100 & 10.4 & 12 & 100 & 10.9 & Yes & - \\
\hline Kumar et al. [75] & 36 & Child & 18 & 100 & 9.6 & 18 & 100 & 9.7 & Yes & $\begin{array}{l}\text { No learning } \\
\text { disability }\end{array}$ \\
\hline Lim et al. [76] & 58 & - & 29 & 100 & 13.8 & 29 & 100 & 14.4 & No & No dyslexia \\
\hline McAlonan et al. [77] & 59 & Child & 28 & 100 & 9.9 & 31 & 100 & 9.6 & Yes & - \\
\hline Montes et al. [78] & 40 & Adult & 20 & 50 & 29.0 & 20 & 50 & 27.6 & No & - \\
\hline $\begin{array}{l}\text { Moreno-Alcazar } \\
\text { et al. [79] }\end{array}$ & 88 & Adult & 44 & 66 & 31.6 & 44 & 66 & 32.6 & No & - \\
\hline Overmeyer et al. [80] & 34 & Child & 18 & 83 & 10.4 & 16 & 94 & 10.3 & Yes & $\begin{array}{l}\text { No learning } \\
\text { disability }\end{array}$ \\
\hline $\begin{array}{l}\text { Roman-Urrestarazu } \\
\text { et al. [81] }\end{array}$ & 83 & Adult & 49 & 76 & 22.2 & 34 & 50 & 22.9 & No & - \\
\hline Sasayama et al. [82] & 35 & Child & 18 & 72 & 10.6 & 17 & 71 & 10.0 & Yes & $\begin{array}{l}\text { No learning } \\
\text { disability }\end{array}$ \\
\hline Van Wingen et al. [83] & 29 & Adult & 14 & 100 & 32.0 & 15 & 100 & 37.0 & Yes & - \\
\hline $\begin{array}{l}\text { Villemonteix et al. } \\
\text { (med naïve group) [84] }\end{array}$ & 57 & Child & 33 & 55 & 10.3 & 24 & 50 & 10.0 & No & - \\
\hline $\begin{array}{l}\text { Villemonteix et al. } \\
\text { (med group) [84] }\end{array}$ & 44 & Child & 20 & 80 & 10.4 & 24 & 50 & 10.0 & No & - \\
\hline Yang et al. [85] & 114 & Child & 57 & 61 & 11.1 & 57 & 60 & 11.7 & Yes & - \\
\hline $\begin{array}{l}\text { Totals or sample } \\
\text { size-weighted averages }\end{array}$ & 1661 & & 898 & 76 & 16.5 & 763 & 71 & 16.6 & & \\
\hline \multicolumn{11}{|l|}{ Dyslexia } \\
\hline Brambati et al. [86] & 21 & - & 10 & 50 & 31.6 & 11 & 45 & 27.4 & Yes & No psychiatric \\
\hline Brown et al. [87] & 30 & Adult & 16 & 100 & 24.0 & 14 & 100 & $\begin{array}{l}\text { matched to clinical } \\
\text { grp }\end{array}$ & No & No ADHD \\
\hline Eckert et al. [88] & 26 & Child & 13 & 100 & 11.4 & 13 & 100 & 11.3 & Yes & No psychiatric \\
\hline $\begin{array}{l}\text { Evans et al. } \\
\text { (male adults) [89] }\end{array}$ & 28 & Adult & 14 & 100 & 42.9 & 14 & 100 & 41.1 & Yes & $\begin{array}{l}\text { No severe } \\
\text { psychiatric }\end{array}$ \\
\hline
\end{tabular}


Table 1 Characteristics of studies included in the meta-analysis (Continued)

\begin{tabular}{|c|c|c|c|c|c|c|c|c|c|c|}
\hline \multirow[t]{2}{*}{ Study (reference) } & \multirow{2}{*}{$\begin{array}{l}\text { Total } \\
N\end{array}$} & \multirow{2}{*}{$\begin{array}{l}\text { Age } \\
\text { group } \\
\text { analysis }\end{array}$} & \multicolumn{3}{|c|}{ Clinical group } & \multicolumn{3}{|c|}{ Control group } & \multirow{2}{*}{$\begin{array}{l}\text { Included } \\
\text { in brain } \\
\text { volume } \\
\text { corrected } \\
\text { analysis }\end{array}$} & \multirow{2}{*}{$\begin{array}{l}\text { Comorbidity } \\
\text { with dyslexia } \\
\text { or ADHD noted in } \\
\text { exclusion criteria }\end{array}$} \\
\hline & & & $\bar{N}$ & $\begin{array}{l}\% \\
\text { male }\end{array}$ & $\begin{array}{l}\text { Mean age } \\
\text { (years) }\end{array}$ & $N$ & $\begin{array}{l}\% \\
\text { male }\end{array}$ & Mean age (years) & & \\
\hline $\begin{array}{l}\text { Evans et al. } \\
\text { (female adults) [89] }\end{array}$ & 26 & Adult & 13 & 0 & 34.0 & 13 & 0 & 27.9 & Yes & $\begin{array}{l}\text { No severe } \\
\text { psychiatric }\end{array}$ \\
\hline $\begin{array}{l}\text { Evans et al. } \\
\text { (male children) [89] }\end{array}$ & 30 & Child & 15 & 100 & 9.6 & 15 & 100 & 8.3 & Yes & $\begin{array}{l}\text { No severe } \\
\text { psychiatric }\end{array}$ \\
\hline $\begin{array}{l}\text { Evans et al. } \\
\text { (female children) [89] }\end{array}$ & 34 & Child & 17 & 0 & 10.1 & 17 & 0 & 9.1 & Yes & $\begin{array}{l}\text { No severe } \\
\text { psychiatric }\end{array}$ \\
\hline Hoeft et al. [90] & 38 & - & 19 & 53 & 14.4 & 19 & 53 & 14.4 & Yes & No psychiatric \\
\hline Jednoróg et al. [91] & 236 & Child & 130 & 57 & 10.3 & 106 & 48 & 10.2 & Yes & No ADHD \\
\hline Kronbichler et al. [92] & 28 & - & 13 & 100 & 15.9 & 15 & 100 & 15.5 & Yes & No psychiatric \\
\hline Liu et al. [93] & 36 & Child & 18 & 72 & 11.8 & 18 & 83 & 11.8 & Yes & No ADHD \\
\hline Silani et al. [94] & 64 & Adult & 32 & 100 & 24.4 & 32 & 100 & 26.3 & No & - \\
\hline Siok et al. [95] & 32 & Child & 16 & 50 & 11.0 & 16 & 81 & 11.0 & Yes & No ADHD \\
\hline Steinbrink et al. [96] & 16 & Adult & 8 & 75 & 20.1 & 8 & 75 & 23.7 & Yes & No psychiatric \\
\hline Tamboer et al. [97] & 94 & Adult & 37 & 16 & 20.6 & 57 & 12 & 20.3 & Yes & No ADHD \\
\hline $\begin{array}{l}\text { Vinckenbosch } \\
\text { et al. [98] }\end{array}$ & 23 & Adult & 13 & 100 & Adults & 10 & 100 & Adults & Yes & No ADHD \\
\hline Xia et al. [99] & 48 & Child & 24 & 58 & 12.5 & 24 & 50 & 12.5 & No & No psychiatric \\
\hline Yang et al. [100] & 23 & Child & 9 & 33 & 12.6 & 14 & 43 & 12.3 & Yes & No ADHD \\
\hline $\begin{array}{l}\text { Totals or Sample } \\
\text { size-weighted averages }\end{array}$ & 833 & & 417 & 61 & 16.4 & 416 & 57 & 16.5 & & \\
\hline
\end{tabular}

Based on our assessment of the existing studies, we find it more likely that the ADHD sample has undetected dyslexia comorbidity than vice versa, based on the screening procedures (see Table 1; Additional file 2: Table S2).

\section{Anatomic likelihood estimate (ALE) meta-analysis}

The ALE meta-analysis method for neuroimaging studies, originally described by Turkeltaub et al. [105], uses a coordinate-based meta-analytic strategy. It treats each set of reported peak coordinates as the center of a probability distribution, in order to deal with inter-study differences in scanning parameters and imaging analyses. Newer versions of GingerALE software (version 2.3.6, www.brainmap.org/ ale, [106-108]) incorporate random effects analysis to look for convergence between experiments. This procedure also adjusts the size of the Gaussian filter for the foci based on the number of participants in a study; smaller studies are blurred with a larger full-width half-maximum (FWHM) size than larger studies (e.g., foci emerging from a study with 10 participants have a $10-\mathrm{mm}$ FWHM applied, as compared with a study of 50 participants, in which a 8.75-mm FWHM is applied). We used the analysis option that limits the effects of any single experiment on the ALE results [108].

Text files were generated that contained the gray matter (GM) foci reported in each study for the clinical group vs. typically developing (TD) group comparison, with separate files for each clinical group $>$ TD and clinical group $<\mathrm{TD}$. This yielded four separate analyses: $\mathrm{ADHD}>\mathrm{TD}, \mathrm{ADHD}<\mathrm{TD}$, dyslexia $>\mathrm{TD}$, and dyslexia $<\mathrm{TD}$. Coordinate foci files entered into this meta-analysis are published with this article (see Additional files 4, 5, 6 and 7). A conjunction analysis was used to evaluate the regions where the clinical groups show similar structural differences compared to the TD groups. Foci in Talairach space were converted to MNI space using the appropriate transform depending on the original data analysis: the relevant tal2icbm transform [109] was applied to foci that were analyzed in SPM or FSL, and foci that were reported in Talairach space that had been transformed from MNI space using the Brett transform were converted back to MNI space using the Brett transform (tal2mni). When foci were located outside the mask for the analysis, coordinates were adjusted to both fit within the mask and to conform to the anatomical region identified in the original publication. In this case, only one set of coordinates from Hoeft et al. [90] required adjustment of the $x$ coordinate from 73.7 to 70 (shift of $3.7 \mathrm{~mm}$ ), which is in the mean range of the adjustment performed in Fox et al. [110]. As noted above, the foci were blurred with a full-width half-maximum (FWHM) calculated based on the sample size of each study. A modeled activation (MA) map was created 
using the foci of each study by taking the maximum across each focus' Gaussian [108], and the ALE image represents the union of all the MA maps. The null distribution of the ALE statistic at each voxel was then determined [107].

\section{Analyses}

\section{Within-disorder ALE analyses}

First, the ALE maps representing coordinates from the ADHD vs. TD and dyslexia vs. TD studies were generated at two thresholds (1) an a priori more conservative threshold: $p<.001$ (uncorrected) with a minimum cluster size $(k)$ of 50, and (2) a post-hoc more lenient threshold: $p<.005$ (uncorrected), $k=50$. This yielded four ALE maps (dyslexia $<\mathrm{TD}$, dyslexia $>\mathrm{TD}, \mathrm{ADHD}<\mathrm{TD}$, and $\mathrm{ADHD}>\mathrm{TD}$ ) that highlight the regions where the literature indicates
GM differences in each disorder (Tables 2 and 3). Because these ALE maps were being used as input to a conjunction analysis with its own statistical correction parameters (described next), we used uncorrected ALE maps at this step to ensure that we did not miss any potential areas of convergent GM differences by thresholding the ALE maps too strictly at this first stage. We selected $p_{\text {uncorrected }}<.001$ $(k=50)$ as an a priori threshold and then relaxed the threshold post-hoc to $p_{\text {uncorrected }}<.005(k=50)$ to ensure that we did not miss any potential areas of conjunction that could be hypothesis-generating for future work, given that this is the first meta-analysis of dyslexia/ADHD gray matter overlap. We note throughout the manuscript which findings met our more conservative and more lenient thresholds for statistical significance.

Table 2 Gray matter differences in ADHD $(p<.001, k=50)$

\begin{tabular}{|c|c|c|c|c|c|c|c|}
\hline & Cluster \# & Volume $\left(\mathrm{mm}^{3}\right)$ & ALE Value & $x$ & $y$ & $z$ & Label \\
\hline \multirow[t]{11}{*}{$\mathrm{ADHD}<\mathrm{TD}$} & 1 & 552 & 0.013433 & 26 & 6 & 6 & Right putamen \\
\hline & 2 & 272 & 0.014215 & -58 & 6 & -2 & Left superior temporal gyrus \\
\hline & 3 & 144 & 0.011178 & 16 & -32 & 44 & Right cingulate gyrus \\
\hline & 4 & 120 & 0.011226 & -8 & -10 & 48 & Left cingulate gyrus \\
\hline & 5 & 88 & 0.010493 & -22 & -4 & -26 & Left amygdala \\
\hline & 6 & 56 & 0.01083 & -26 & 16 & -24 & Left inferior frontal gyrus \\
\hline & 7 & 56 & 0.010126 & 10 & 30 & -20 & Right medial frontal gyrus / gyrus rectus \\
\hline & 8 & 56 & 0.010821 & 2 & 22 & -2 & Right caudate head \\
\hline & 9 & 56 & 0.010804 & 28 & 70 & -2 & Right superior orbitofrontal gyrus \\
\hline & 10 & 56 & 0.010802 & -14 & 52 & 14 & Left superior frontal gyrus \\
\hline & 11 & 56 & 0.010811 & -40 & -6 & 56 & Left precentral gyrus \\
\hline \multirow[t]{18}{*}{$A D H D>T D$} & 1 & 160 & 0.007913 & 33 & -76 & 4 & Right mid-occipital gyrus \\
\hline & 2 & 160 & 0.007913 & -14 & -84 & 37 & Left cuneus \\
\hline & 3 & 160 & 0.007913 & 21 & -42 & 54 & Right precuneus \\
\hline & 4 & 160 & 0.007913 & -17 & 12 & 58 & Left superior frontal gyrus \\
\hline & 5 & 160 & 0.007918 & -6 & -20 & 66 & Left paracentral lobule \\
\hline & 6 & 152 & 0.008282 & -26 & -28 & 70 & Left postcentral gyrus \\
\hline & 7 & 152 & 0.00817 & 6 & -10 & 64 & Right supplementary motor area \\
\hline & 8 & 144 & 0.007837 & -14 & -38 & 60 & Left precuneus \\
\hline & 9 & 96 & 0.007112 & -2 & -15 & 5 & Left thalamus, medial dorsal nucleus \\
\hline & 10 & 96 & 0.007271 & -13 & -27 & 40 & Left cingulate gyrus \\
\hline & 11 & 96 & 0.007665 & 30 & -7 & 69 & Right precentral/superior frontal gyrus \\
\hline & 12 & 96 & 0.007665 & 27 & -35 & 74 & Right postcentral gyrus \\
\hline & 13 & 72 & 0.006635 & -16 & -34 & 68 & Left postcentral gyrus \\
\hline & 14 & 64 & 0.007051 & -49 & -21 & 23 & Left insula \\
\hline & 15 & 64 & 0.007051 & -15 & -45 & 37 & Left posterior cingulate/precuneus \\
\hline & 16 & 64 & 0.006901 & 45 & -15 & 37 & Right postcentral gyrus \\
\hline & 17 & 56 & 0.007732 & -14 & -54 & 46 & Left precuneus \\
\hline & 18 & 56 & 0.007732 & -34 & -34 & 48 & Left postcentral gyrus \\
\hline
\end{tabular}


Table 3 Gray matter differences in dyslexia $(p<.001, k=50)$

\begin{tabular}{|c|c|c|c|c|c|c|c|}
\hline & Cluster \# & Volume $\left(\mathrm{mm}^{3}\right)$ & ALE value & $x$ & $y$ & $z$ & Label \\
\hline \multirow[t]{12}{*}{ Dyslexia $<T D$} & 1 & 336 & 0.010974 & -48 & -46 & 28 & Left supramarginal gyrus \\
\hline & 2 & 312 & 0.011585 & -56 & 8 & -16 & Left superior temporal gyrus \\
\hline & 3 & 192 & 0.010177 & -26 & -50 & -32 & Left cerebellum lobule VI \\
\hline & 4 & 104 & 0.008865 & 36 & -64 & -10 & Right inferior occipital gyrus \\
\hline & 5 & 96 & 0.009758 & -5 & -20 & 5 & Left thalamus, medial dorsal nucleus \\
\hline & 6 & 96 & 0.008935 & -14 & 14 & 6 & Left caudate body \\
\hline & 7 & 80 & 0.009177 & 38 & 47 & -12 & Right orbitofrontal gyrus \\
\hline & 8 & 80 & 0.008973 & -56 & -52 & 2 & Left middle temporal gyrus \\
\hline & 9 & 80 & 0.009207 & 52 & -52 & 22 & Right superior temporal / supramarginal gyrus \\
\hline & 10 & 80 & 0.009177 & 20 & 39 & 40 & Right superior frontal gyrus \\
\hline & 11 & 64 & 0.008617 & -48 & -26 & 22 & Left insula \\
\hline & 12 & 56 & 0.009506 & 10 & 14 & 8 & Right caudate body \\
\hline \multirow[t]{13}{*}{ Dyslexia >TD } & 1 & 576 & 0.009831 & 14 & -48 & 44 & Right precuneus \\
\hline & 2 & 280 & 0.008859 & -57 & -53 & 42 & Left inferior parietal lobule \\
\hline & 3 & 224 & 0.009177 & -32 & -76 & -23 & Left cerebellum crus I \\
\hline & 4 & 224 & 0.009177 & 50 & -7 & -12 & Right superior temporal gyrus \\
\hline & 5 & 224 & 0.008969 & -60 & -60 & 5 & Left middle temporal gyrus \\
\hline & 6 & 152 & 0.007361 & -6 & 50 & 18 & Left medial superior frontal gyrus \\
\hline & 7 & 152 & 0.007361 & 6 & 12 & 54 & Right supplementary motor area \\
\hline & 8 & 96 & 0.006936 & 12 & 51 & 5 & Right medial superior frontal gyrus \\
\hline & 9 & 96 & 0.006936 & 20 & 11 & 51 & Right medial frontal gyrus \\
\hline & 10 & 80 & 0.007146 & -50 & -26 & 3 & Left superior temporal gyrus \\
\hline & 11 & 80 & 0.007146 & 56 & 0 & 23 & Right precentral gyrus \\
\hline & 12 & 80 & 0.007146 & 16 & -38 & 60 & Right paracentral lobule \\
\hline & 13 & 80 & 0.006447 & 16 & -18 & 66 & Right precentral gyrus \\
\hline
\end{tabular}

\section{Conjunction analysis}

Second, to determine any statistically significant overlap between areas of reduced GM in both ADHD and dyslexia, we conducted a conjunction analysis for the $\mathrm{ADHD}<\mathrm{TD}$ and dyslexia $<\mathrm{TD}$ results using the more conservatively ( $\left.p_{\text {uncorrected }}<.001, k=50\right)$ and more leniently ( $p_{\text {uncorrected }}<.005, k=50$ ) thresholded maps. The conjunction analysis was thresholded at a false discovery rate (FDR) of $p<.05$ (estimated with 5000 permutations of the pooled dataset) with a minimum cluster size of 50 . We did not conduct a conjunction analysis for the ADHD $>$ TD and dyslexia $>$ TD output, because visual inspection of both thresholded maps showed no evidence of overlap between the ADHD>TD and dyslexia>TD maps.

\section{Impact of total brain volume}

To evaluate the robustness of the main conjunction results, we ran a follow-up analysis that only included studies which (1) covaried for total brain volume or total gray matter volume or (2) explicitly tested for differences in total brain volume or total gray matter volume between groups and found null results. This follow-up analysis ensured that individual ALE maps for dyslexia and ADHD represented the most robust regionally specific findings in these literatures. Of the ADHD studies, 13 of 22 accounted for total brain or gray matter volume. Of the dyslexia studies, 12 of 15 accounted for total brain or gray matter volume (see Table 1).

\section{Impact of age}

We examined the potential impact of age on casecontrol GM differences by repeating the analyses with studies grouped based on whether the participants were children (mean of clinical and control group ages between 6 years, 0 months, and 12 years, 11 months; no adults included in the study) or adults (18 years and up). Studies that included both children and adults in the sample were not included in this sub-analysis. To our knowledge, the GingerALE software does not include functionality to test moderation directly, so we 
proceeded by analyzing these age-based subgroups separately. Among the ADHD group contrasts, 12 met our inclusion criteria for the child analysis while 6 investigated adult participants. Among the dyslexia group contrasts, 8 studies met our inclusion for the child analysis, while 7 investigated adult participants (see Table 1 for designation of which studies were included in the child or adult analysis). There were not enough studies to create a separate adolescent age group.

The ALE maps for $\mathrm{ADHD}<\mathrm{TD}_{\text {children }}, \mathrm{ADHD}<\mathrm{TD}_{\text {adults, }}$, dyslexia $<\mathrm{TD}_{\text {children }}$, and dyslexia $<\mathrm{TD}_{\text {adults }}$ were generated and thresholded at the same more conservative ( $p_{\text {uncor- }}$ rected $<.001, k=50)$ and more lenient ( $p_{\text {uncorrected }}<.005$, $k=50$ ) thresholds. For the age analysis, the number of studies reporting increased GM in both disorders were too few to conduct meaningful analyses. As in the main analysis, a conjunction analysis of the child dyslexia and ADHD maps and the adult dyslexia and ADHD maps was conducted using FDR $p<.05$ (estimated with 5000 permutations of the pooled dataset) with a minimum cluster size of 50 .

\section{Data visualization and reporting}

The data were visualized using MRIcroGL (http://www. cabiatl.com/mricrogl/) with the thresholded ALE maps as the overlay and the MNI152 brain as the underlay. The size, extent, peak coordinates, and ALE values for each statistically significant cluster are reported in Tables 2 and 3.

\section{Results}

\section{Gray matter differences in ADHD}

Table 2 provides the details of regions in which participants with ADHD showed differences in GM relative to a typically developing comparison group at the more conservative $p<.001, k=50$ threshold. Reduced GM in ADHD was evident in the right basal ganglia (caudate and putamen), left superior temporal gyrus, cingulate cortex, left amygdala, and several frontal cortical regions (Fig. 2, yellow-orange). Increased GM in ADHD was found in areas associated with sensorimotor planning and execution (supplementary motor area, pre- and postcentral gyri), the thalamus, as well as occipital (middle occipital gyrus) and parietal (posterior cingulate, cuneus, precuneus) areas (Fig. 3, red).

\section{Gray matter differences in dyslexia}

Table 3 shows regions where the ALE analyses showed GM differences in dyslexia at the more conservative $p<.001, k=50$ threshold. Reduced GM was evident in dyslexia in left-hemisphere middle and superior temporal regions, inferior parietal regions, and cerebellum (lobule VI); right medial and orbital frontal regions; and the caudate bilaterally (Fig. 2, violet). Increased GM in dyslexia compared with controls was evident in the left supramarginal gyrus/inferior parietal lobule, middle temporal gyrus, and cerebellum (Crus I); right precuneus, supplementary motor area, and precentral gyrus; and medial frontal regions (Fig. 3, blue).

\section{Conjunction analysis}

We tested for regions of overlap between the areas of GM reduction in ADHD and dyslexia using both the more conservatively $\left(p_{\text {uncorrected }}<.001, k=50\right)$ and more leniently thresholded ( $\left.p_{\text {uncorrected }}<.005, k=50\right)$ ALE maps. There was no statistically significant conjunction of the ALE maps using the more conservative threshold $(p<.001, k=50)$. Figure 4 shows the ALE maps at the more lenient threshold $(p<.005, k=50)$. While there was some visual overlap in the caudate bilaterally, left hippocampus, left cerebellum, and bilateral ventromedial prefrontal cortex (vmPFC), the statistical conjunction analysis (FDR $p<.05, k=50,5000$ permutations) revealed that only the right caudate survived statistical correction $\left(k=112\right.$, ALE $8.48 \times 10^{-3}$, MNI coordinates $x=10, y=14$, and $z=8$; see Fig. 4).

GingerALE does not have a quantitative way to determine how individual studies contribute to a conjunction result, so we used visual inspection of the ALE maps and evaluation of the reported coordinates to investigate the conjunction result. While there were several studies of dyslexia and ADHD that reported coordinates in the right caudate, the studies that reported coordinates closest to the conjunction peak were the Yang et al. [85] ADHD study $(x=10, y=12, z=7)$ and the Tamboer et al. [97] dyslexia study $(x=10, y=14, z=8)$. Notably, the Tamboer et al. dyslexia study specifically excluded comorbid ADHD, so it is unlikely that high rates of comorbid ADHD in the dyslexia sample can explain the conjunction. Both the Yang $(n=114)$ and Tamboer $(n=$ 94) studies were the second largest VBM studies in their respective literatures.

\section{Impact of total brain volume}

To test the robustness of the conjunction in the right caudate, we re-ran the conjunction analyses excluding studies that did not correct for total brain volume (see Table 1). This analysis used the more leniently thresholded ALE maps $\left(p_{\text {uncorrected }}<.005, k=50\right)$. The right caudate remained the only statistically significant region of conjunction between $\mathrm{ADHD}<\mathrm{TD}$ and dyslexia $<\mathrm{TD}$ maps (FDR $p<.05,5000$ permutations; $k=120$, ALE $8.48 \times 10^{-3}$, MNI coordinates $x=10, y=14, z=8$ ).

\section{Impact of age}

When analyses were restricted to studies of dyslexia and ADHD in adults, there was no overlap in reduced GM at either the conservative $\left(p_{\text {uncorrected }}<.001, k=50\right)$ or 


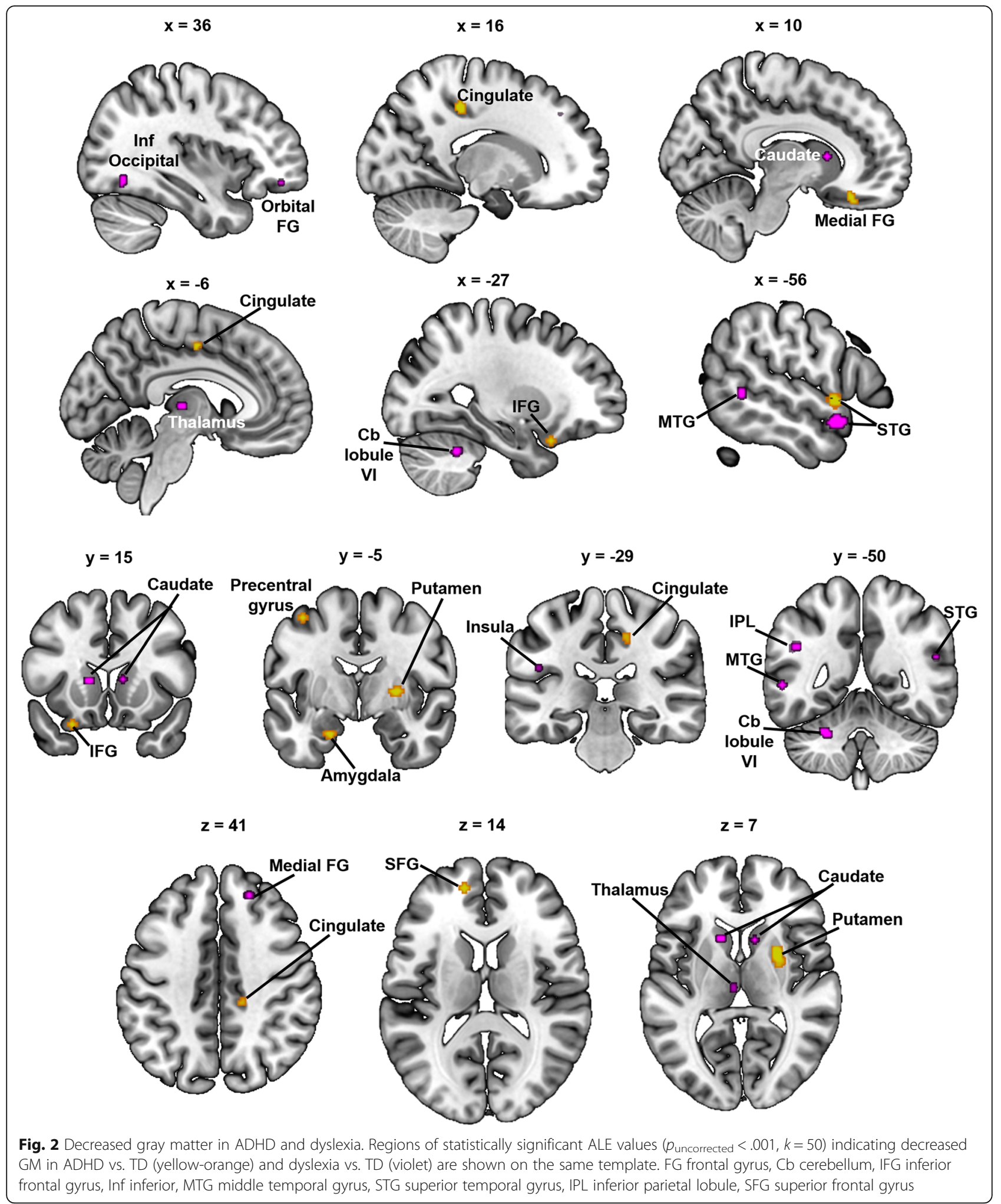

liberal ( $\left.p_{\text {uncorrected }}<.005, k=50\right)$ thresholds. In children, there was no overlap between the regions showing less GM in the clinical groups relative to the TD groups at $p_{\text {uncorrected }}<.001$. When the maps were thresholded at $p_{\text {uncorrected }}<.005$, there was a small cluster in the left middle frontal gyrus/supplementary motor area where 


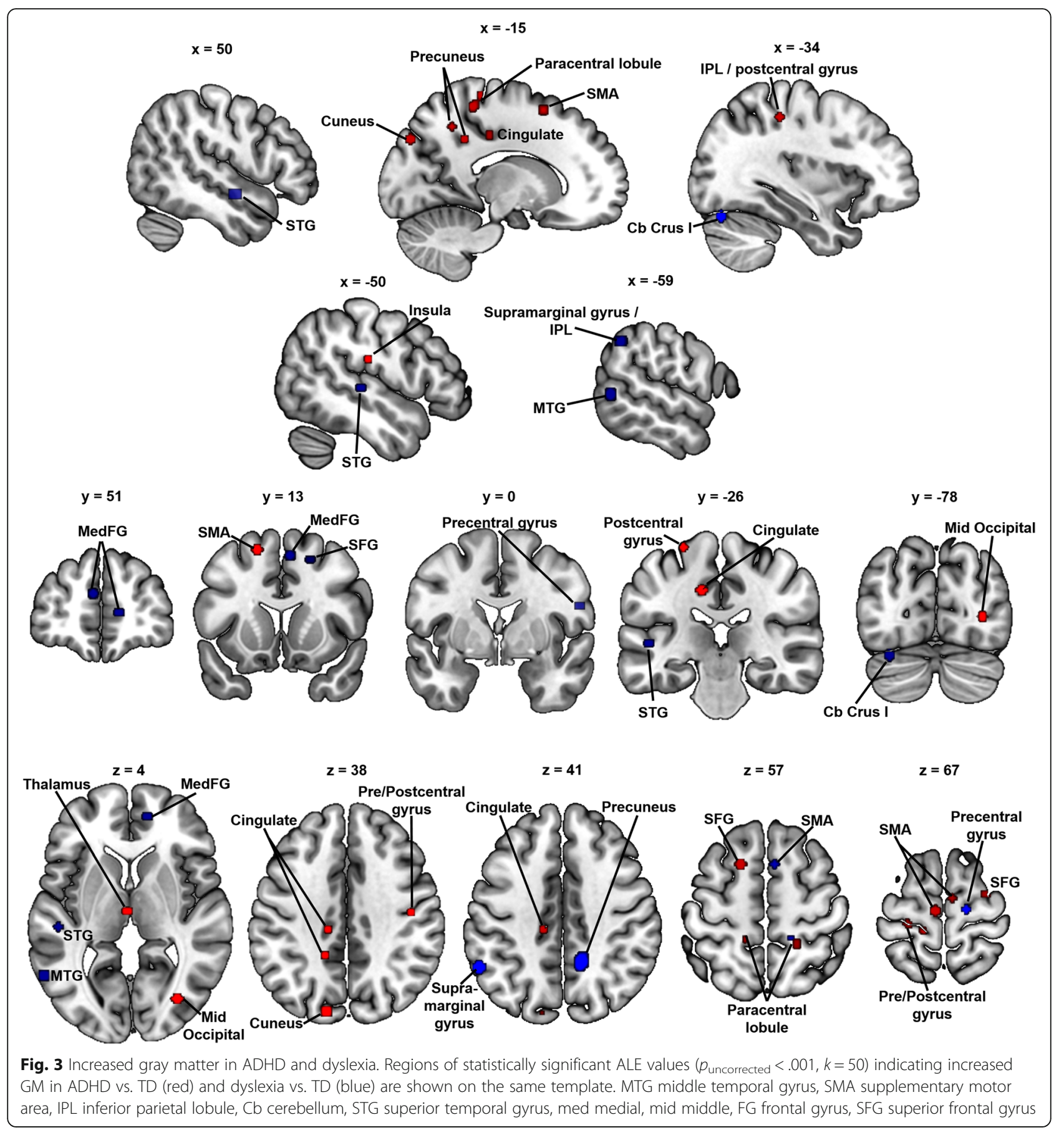

there was overlap between reduced GM in both groups $\left(k=64\right.$, ALE $6.75 \times 10^{-3}$, MNI coordinates $x=-28, y=$ 19, $z=43$ ) (see Additional file 3: Table S3).

\section{Discussion}

This study presents the first meta-analysis of overlap in gray matter differences between dyslexia and ADHD. The rationale for this "conjunction" approach to the meta-analysis is derived from existing multiple deficit models of dyslexia and ADHD [3, 7, 13, 14]. In these conceptualizations, the comorbidity of dyslexia and ADHD is believed to arise, at least partly, from shared genetic factors that may manifest in shared cognitive risks, such as processing speed $[13,18]$ and executive functions [17]. The current study fills a gap at the neural level of analysis by attempting to identify overlapping gray matter correlates associated with both disorders. 


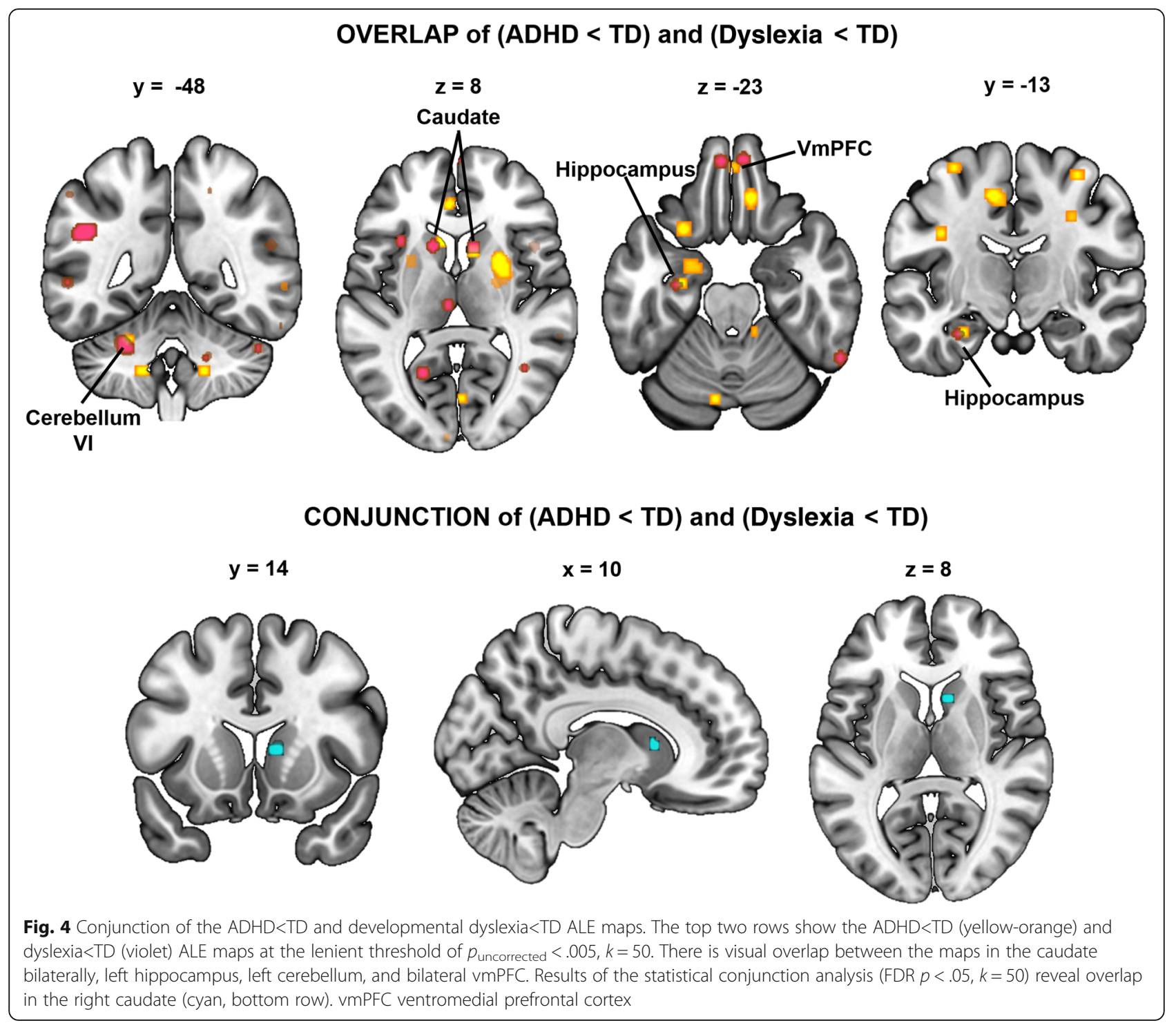

A general theme emerging from the results of this meta-analysis is that there is a surprising lack of overlap between the disorders. The same pattern was true when we restricted the analyses to age-specific comparisons for children and adults. While there were isolated findings that emerged using our lenient thresholds, it was notable that the overall pattern was one of the distinctiveness of gray matter correlates in dyslexia and ADHD. Here, we discuss (1) the state of the VBM literature in both disorders, (2) regions of convergence, and (3) why shared neural correlates may have been difficult to find.

\section{VBM literature in dyslexia and ADHD}

A precondition for examining overlapping structural differences in dyslexia and ADHD is that the individual literatures are sufficiently advanced to show good convergence within disorder before cross-disorder convergence can be assessed. Because both literatures have had replication difficulties $[39,42]$, we will first consider the correspondence of our disorder-specific results with previous meta-analyses.

\section{Meta-analyses of VBM studies in dyslexia}

There have been three meta-analyses of VBM studies in dyslexia [47-49]. Richlan et al. [49] and Linkersdorfer et al. [48] each included 9 studies, while Eckert et al. [47] included 11 studies. The overlap in the studies included in previous meta-analyses and the current meta-analysis ranges from $46 \%-53 \%$. Richlan et al. [49] reported gray matter reduction in the right superior temporal gyrus and the left superior temporal sulcus; regional gray matter 
reductions in left ventral occipitotemporal and left cerebellar regions were too scattered for reliable meta-analytic clustering. Linkersdorfer et al. [48] reported gray matter reductions in the left fusiform gyrus (extending into the left inferior temporal gyrus), bilateral supramarginal gyrus (right cluster extended to the posterior portion of the superior temporal gyrus), and bilateral cerebellum (lobule VI). The most recent meta-analysis by Eckert et al. [47] reported gray matter reductions in left orbitofrontal cortex/inferior frontal gyrus, left posterior superior temporal sulcus/middle temporal gyrus, and right cerebellum. The Eckert et al. study also included a direct VBM analysis of the largest consortium dataset to date $(N=164$ children with dyslexia; $N=129$ controls). In contrast to the meta-analytic results, the direct analysis did not detect any statistically significant regions of reduced gray matter after controlling for total gray matter volume [47]. Taken together, across studies there is some consistency in areas implicated by at least two of the meta-analyses, including left superior temporal/temporoparietal regions, left ventral occipitotemporal regions, right superior temporal regions, and bilateral cerebellar regions. These findings in the left hemisphere show good convergence with the two posterior neural systems in the left hemisphere that have been repeatedly implicated in dyslexia. Our meta-analytic results were consistent with previous meta-analyses in the left and right temporoparietal regions and left cerebellar lobule VI. However, we also note the null findings from Eckert et al.'s [47] consortium VBM analysis which suggests that this literature continues to have inconsistencies [39] that should be addressed by larger imaging samples and continued metaanalytic strategies.

\section{Meta-analyses of VBM studies in ADHD}

The ADHD VBM literature has been meta-analyzed in four previous studies [32, 40,50,51]. The overlap in the studies included in previous meta-analyses and the current meta-analysis ranges from $18 \%$ study overlap with the earliest meta-analysis [50] to $68 \%$ study overlap with the most recent meta-analysis [32]. The first meta-analysis included 7 studies [50] and found gray matter reductions in the right putamen/globus pallidus in individuals with ADHD compared to controls. Nakao et al. [51] included 14 studies, and the most robust finding was reduced gray matter volume in the right basal ganglia, including the putamen, globus pallidus, and the caudate nucleus. Frodl et al. [40] included 11 studies, and also reported reduced gray matter in the basal ganglia (right globus pallidus, right putamen) as well as bilaterally in the anterior cingulate cortex (ACC). The most recent meta-analysis by Norman et al. [32] (27 studies) showed decreased gray matter in the right putamen/pallidum/insula, right caudate nucleus, ventromedial orbitofrontal cortex/ventromedial prefrontal cortex/rostral ACC, and left occipital lobe. Taken together, regions in right basal ganglia structures and ACC are consistently reduced in ADHD across studies, which is in line with hypotheses of fronto-striatal dysfunction in ADHD. Likewise, our results showed reduced gray matter in right basal ganglia structures (putamen, caudate) and medial frontal regions.

\section{Potential regions of overlap}

In the primary conjunction analysis, there was no statistically significant conjunction between our more conservatively thresholded ALE maps $(p<.001, k=50)$, but decreased gray matter in the right caudate emerged as a region of statistically significant conjunction between dyslexia and ADHD when using our leniently thresholded ALE maps $(p<.005, k=50)$. This overlap in the caudate remained significant in our follow-up analysis of studies accounting for total brain volume, suggesting that this regional difference is specific and not attributable to global structural differences. These results suggest that this region is worth further exploration regarding its potential relevance to ADHD and dyslexia. In fact, our confidence in this finding has increased due to a recently published paper reporting converging results [30]. Jagger-Rickels et al. [30] recently published the first VBM study of comorbid dyslexia+ADHD where they compared children with dyslexia only $(N=17)$, ADHD only $(N=41)$, and dyslexia+ADHD $(N=16)$ to controls $(N=32)$. They reported that regions of the right caudate showed smaller volumes in all three clinical groups, consistent with the results of this meta-analysis and the notion of the right caudate as a shared neural correlate of both disorders.

In ADHD, the caudate has been a long-standing region of interest in both structural and functional neuroimaging studies as a critical component of frontal-striatal circuits implicated in ADHD (i.e., [111]). Decreases in caudate volume in ADHD are one of the most consistent structural findings reported in ADHD [32, 40, 50-52]. The caudate also shows functional differences in ADHD. For example, a recent meta-analysis of fMRI studies of ADHD reported under-activation of the right caudate relative to controls during go/no-go tasks [41]. Structural and functional differences in the caudate could underpin executive function impairment in ADHD.

While striatal dysfunction has been a central focus of investigation in ADHD, it has only recently emerged as a region of interest in dyslexia [87, 97, 112]. Because of this, it is not clear how striatal structural differences might be related to dyslexia. Tamboer et al. [97] showed that the same region in the right caudate nucleus as we report in the current study (MNI $x=10, y=14, z=8$ ) 
was significantly correlated $(r=.61)$ with a rhyme/confusion factor. The rhyme/confusion factor includes a Dutch-English rhyming task [97]. The authors speculated that the correlation might be related to executive dysfunction, because the rhyming task required switching between languages. This interpretation is consistent with the notion that fronto-striatal dysfunction may be related to executive function deficits in both dyslexia and ADHD.

The striatum has also emerged as a region of interest in functional neuroimaging studies of dyslexia. Meta-analytic studies have reported consistent hyperactivation in several frontal-striatal regions, including the bilateral striatum (both putamen and caudate) [113-115]. These hyperactivations have been interpreted as "compensatory," though specific mechanisms remain unclear. Hancock et al. [112] explored three specific hypotheses about these hyperactivations, given the role of the striatum in (1) articulatory processing, (2) phonological processing, and (3) implicit/ procedural learning. They found the strongest level of support for overlap of dyslexia hyperactivations in frontostriatal circuits with articulation functional maps, suggesting compensatory activity potentially related to subvocalizations during reading. While articulatory processes were the leading hypothesis based on their results, it is difficult to conclusively rule out the other hypotheses. The authors did not explore potential overlap with executive functioning maps, which also remains a competing hypothesis.

Taken together, the role of the caudate in dyslexia remains unclear, but executive functions and procedural learning are two candidate cognitive constructs that may overlap between dyslexia and ADHD. There is extensive neuropsychological evidence documenting executive dysfunction in both dyslexia and ADHD, especially in working memory, inhibition, and sustained attention, which depend on frontal-striatal circuitry. Procedural learning is a newer hypothesis that deserves further scrutiny [116, 117]. There is emerging evidence for procedural learning deficits in dyslexia, most notably from a meta-analysis of the most widelyused procedural sequence learning task, the serial reaction time task [118]. Procedural learning deficits have also been hypothesized in ADHD, partly because procedural learning depends on frontal-striatal circuitry. The evidence-base is small at present, but there are promising leads $[119,120]$. In summary, the overlap between dyslexia and ADHD in the right caudate might point to impairments in procedural learning and/or executive functions that are risk factors for both disorders.

Our analyses of age-based subgroups showed an overlap in the left middle frontal gyrus/supplementary motor area between children with ADHD and children with dyslexia at our liberal statistical threshold. This analysis should be interpreted with caution because of the reduced number of contributing studies and the liberal statistical threshold. Nevertheless, we report this finding for hypothesis-generating purposes. A plausible interpretation of this region of overlap is again attributable to shared impairments in executive function in dyslexia and ADHD, due to the critical role of the frontal circuitry in executive functions [121-123], including working memory and inhibitory control.

\section{Evaluating potential explanations for minimal gray matter overlap}

The foregoing discussion focused on regions of overlap, but the overall pattern of results was notable in the specificity of the gray matter correlates in dyslexia and ADHD. How can we understand the overall distinctiveness of the gray matter correlates of dyslexia and ADHD in the context of a strong genetic correlation between the two disorders, $r_{g} \sim .50-.70$ [7]? There are a few points to consider.

\section{Comorbidity}

First, it appears that the neuroimaging literatures of both disorders have generally sought to recruit "pure" groups. This recruitment strategy does not completely explain the lack of overlap, however, because we can infer from the genetic correlation that a genetic factor influencing dyslexia is also $50-70 \%$ likely to influence ADHD as well (and vice versa). Since both dyslexia and ADHD are known to be complex polygenic disorders likely involving hundreds to thousands of genes [124, 125], many children with "pure" dyslexia and "pure" ADHD should possess a number of genetic risk factors that could be considered "shared" and we would expect these shared genetic factors to influence shared neural systems as well. Thus, a comparison of "pure" disorders is actually the strongest test of the correlated liabilities model. In this context, the fact that we did identify a region of overlap in the right caudate, albeit at more lenient statistical thresholds, is an important hypothesis-generating finding for future work. While a "pure" disorders recruitment strategy may have attenuated the overlap of dyslexia and ADHD in our meta-analysis, we suggest that our main finding of distinctive gray matter differences in ADHD and dyslexia is not entirely attributable to recruitment approach.

\section{Developmental considerations}

Is it possible that our mainly null results could be due to mismatches in age recruitment between dyslexia and ADHD? While dyslexia studies included proportionally more adult samples than ADHD studies $(N=7$ adult 
studies of 15 for dyslexia, $N=6$ adult studies of 22 for ADHD), the sample size-weighted age comparisons indicate that age mismatches are unlikely to be a primary problem $\quad$ (dyslexia $=16.4$ years; $\quad \mathrm{ADHD}=16.5$ years) . Moreover, our follow-up analysis restricting to just child samples and just adult samples where we continued to find largely distinctive patterns across disorders partially addressed this issue. However, with the increase in homogeneity of age, there is a corresponding decrease in sample size and power and so the null findings are less interpretable.

\section{Alternative imaging modalities}

It is possible that VBM is not sufficiently sensitive to detect the overlapping neural correlates of both disorders, which may be better indexed by methods designed to assess structural and functional connectivity or functional signatures under task demands. While there is evidence that gray matter alterations can be correlated with functional abnormalities, the overlap is not complete [48].

\section{Next steps}

If gray matter alterations are not capturing the shared neurobiological risk associated with dyslexia and ADHD, what is the most promising direction for further studies of this question? One promising next step is to use the neuropsychological findings to inform neuroimaging studies of the overlap of these two disorders. For example, processing speed is a construct that has been associated with both disorders and can account for a substantial portion of the comorbidity or covariance $(\sim$ $75 \%)[13,14]$. Moreover, in a previous study, all of the shared genetic influences between reading and inattention symptoms were also shared with processing speed, indicating that processing speed may be a marker of the correlated genetic liability of the two disorders [7]. The most consistent neural correlate of processing speed is white matter volume and integrity, with broad involvement from frontal, parietal, and temporal regions [126]. These associations lead to the hypothesis that compromised white matter integrity may jointly increase risk for reading and attention problems via processing speed impairments. Further work on this hypothesis is needed through individual studies of potential overlapping white matter differences in these disorders.

In terms of the design of neuroimaging studies, there are important next steps to take in characterizing and recruiting comorbid samples to address both shared and specific features of dyslexia and ADHD. While most dyslexia samples screened out ADHD, most ADHD studies did not comment on comorbid dyslexia or learning disabilities. One first step is for neuroimaging studies of dyslexia and ADHD to directly assess ADHD and reading symptoms, respectively. Brief, standardized instruments are available to assess both domains. Direct assessments would be helpful because many studies in the existing literature used parent or self-report of cooccurring diagnoses, and so likely under-estimate the rate of true comorbidity. Direct assessments would also permit the investigation of subclinical variation in comorbid disorders, which is important given that both dyslexia and ADHD are conceptualized as extreme phenotypes on an underlying continuous distribution [127, 128].

The ideal recruitment strategy for investigating the neural correlates of the dyslexia-ADHD comorbidity is to collect individuals with dyslexia, ADHD, dyslexia+ADHD, and typically developing controls. Only a few studies have taken this approach (e.g., $[30,31])$. In the past, such comorbid designs have been used to document differences, not similarities, between groups. However, the correlated liabilities model predicts that all three clinical groups should show similarities in some neural correlates, so it is important that analyses are designed to investigate shared as well as specific neural correlates.

\section{Limitations}

The current results should be considered in light of a few limitations. As with any meta-analysis, our analysis is constrained by the design and statistical decisions of the primary studies. While the neuroimaging field is moving toward larger samples in general, Table 1 shows that it is still quite common to use sample sizes in the range of 20-30 individuals per group, which are likely underpowered for expected effect sizes [39, 42]. Given these power limitations, it remains possible that gray matter correlates with smaller effects have not been reliably detected, and some of these undetected correlates could be overlapping between dyslexia and ADHD.

Relatedly, the ALE meta-analytic approach relies on modeling the peak coordinates reported in studies and does not account for the extent of statistically significant findings (i.e., cluster size). It is possible that this approach leads to a more conservative estimation of potential sample overlap in the cases of studies reporting large clusters which extend well beyond the region that would be modeled by the ALE approach.

Recruitment across studies for dyslexia and ADHD was heterogeneous. For dyslexia, some studies included participants with a previous clinical diagnosis while others established their own empirical criteria on standardized reading measures. Similarly, for ADHD, studies varied in whether they employed clinical diagnoses, standardized diagnostic interviews and/or behavioral rating scales. These recruitment differences likely add to the heterogeneity of the clinical populations, potentially making it more difficult to identify consistent gray matter correlates 
within disorders, and thereby making it more difficult to discern overlaps between the disorders.

It was beyond the scope of this meta-analysis to examine medication effects in ADHD (for a review see [40]), but we note that medication may normalize structural differences in ADHD [51], though this is not a universal finding [42]. If medication does normalize structural differences, this might make it difficult to identify genetically driven overlaps between dyslexia and ADHD. Further studies could focus on the overlap of brain regions associated with family risk for dyslexia and ADHD in preschool children before the onset of reading and before stimulant initiation to more narrowly focus on neurobiological risk factors for both disorders, rather than the consequences of reduced reading experience and stimulant use.

Lastly, it is important to consider the role of publication bias in this meta-analysis. Analytic strategies for identifying publication bias in the neuroimaging literature are still emerging because of the unique challenges associated with this type of data (e.g., [129, 130]). For neuroimaging studies, there are related concerns for the role of "missing" null studies (i.e., the file drawer problem) and concerns for false positives in the published literature [131-133]. In our analysis, the problem of false positives is a larger threat to validity than the file drawer problem. In our coordinate-based meta-analytic framework, null studies do not influence the disorder-specific meta-analytic results because the method tests for spatial convergence of foci across studies against the null hypothesis of random spatial convergence. However, what would weaken the evidence for true convergence are studies that reported multiple false positives. Such random noise would diminish the statistical evidence for convergence of true effects across studies [129]. False positives are likely given the unique characteristics of the neuroimaging literature where there is high pressure to publish because of the expense of studies coupled with multiple decision points in the analysis and a high multiple testing burden [134]. In this case, we must consider the role of confirmation bias such that falsepositive brain associations that are aligned with existing theories are more likely to be published. While we acknowledge the potential role of theory-aligned false positives in both the dyslexia and ADHD literature, we note that the conjunction analysis across the dyslexia and ADHD literatures is somewhat immune to this concern because these literatures have been quite theoretically distinct. It seems unlikely that false positives in both literatures would overlap to give a false positive conjunction. Of course, the most persuasive evidence will come from independent replication in well-powered samples, which shows some initial promise in the case of the right caudate finding [30].

\section{Conclusions}

To our knowledge, the current study is the first to metaanalyze the overlap of gray matter correlates of dyslexia and ADHD. The overall pattern was one of largely distinctive gray matter correlates, although we identified a region of overlap in the right caudate when using our more lenient statistical thresholds. This overlap in the right caudate may be related to shared cognitive correlates in executive functions and/or procedural learning. Our goal was to identify shared gray matter differences in order to contribute to a multi-level understanding to the dyslexia-ADHD comorbidity that spans the genetic, neural, and cognitive levels of analysis. This framework is important not only for the dyslexia-ADHD comorbidity specifically, but also for the broader field of neurodevelopmental disorders where comorbidity is pervasive.

\section{Supplementary information}

Supplementary information accompanies this paper at https://doi.org/10. 1186/s11689-019-9287-8.

Additional file 1. Checklist for neuroimaging meta-analyses

Additional file 2. Detailed characteristics of studies included in the meta-analysis.

Additional file 3. Gray matter differences in ADHD and dyslexia in adults and children $(p<.001, k=50)$

Additional file 4. GingerALE meta-analysis script for ADHD > TD.

Additional file 5. GingerALE meta-analysis script for Dylexia $>$ TD.

Additional file 6. GingerALE meta-analysis script for Dyslexia < TD.

Additional file 7. GingerALE meta-analysis script for $A D H D<T D$.

\section{Abbreviations}

ACC: Anterior cingulate cortex; ADHD: Attention-deficit/hyperactivity disorder; ALE: Anatomic likelihood estimate; Cb: Cerebellum; FDR: False discovery rate; FG: Frontal gyrus; FWHM: Full-width half-maximum; GM: Gray matter; Inf: Inferior; IPL: Inferior parietal lobule; $k$ : Cluster size; MA: Modeled activation; med: Medial; mid: Middle; MNI: Montreal Neurological Institute; MTG: Middle temporal gyrus; PRISMA: Preferred Reporting Items for Systematic Reviews and Meta-analyses; SFG: Superior frontal gyrus; SMA: Supplementary motor area; STG: Superior temporal gyrus; TD: Typically developing controls; VBM: Voxel-based morphometry; vmPFC: Ventromedial prefrontal cortex

\section{Acknowledgements}

The authors would like to acknowledge the students who helped with literature searches for this meta-analysis: Sarah Crennen, Brianne Drury, Stephanie Martin, and Rebecca Slomowitz. Thanks to Mark Eckert and colleagues for providing coordinates for peak clusters from their recent study (Eckert et al. [47]).

\section{Authors' contributions}

LMM and CJS designed the study, assembled the meta-analytic dataset, and interpreted the results. LMM wrote the manuscript. CJS analyzed the data and critically revised the manuscript. All authors read and approved the final manuscript.

\section{Funding}

This work was supported by grants from the National Institutes of Health (NIH): R15HD086662 and P50HD027802. NIH played no role in the design of the study, the collection, analysis, interpretation of the data, or the writing of the manuscript. 


\section{Availability of data and materials}

Meta-analysis coordinates entered into the publicly available GingerALE software (http://www.brainmap.org/ale/) are provided as supplementary files (Additional files 4, 5, 6 and 7). These text files report the gray matter foci for existing dyslexia vs. controls and ADHD vs. controls voxel-based morphometry studies, with separate files for clinical group $>$ controls and clinical group $<$ controls

\section{Ethics approval and consent to participate}

Not applicable

\section{Consent for publication}

Not applicable

\section{Competing interests}

LMM receives book royalties from Guilford Press for the 2 nd and 3rd editions of the textbook, Diagnosing Learning Disorders. CJS has no competing interests.

\section{Author details}

'Department of Psychology, University of Denver, Frontier Hall, 2155 S. Race St., Denver, CO 80208, USA. ${ }^{2}$ Department of Psychology and Center for Behavioral Neuroscience, American University, Washington, DC, USA.

\section{Received: 19 December 2018 Accepted: 4 October 2019}

\section{Published online: 21 November 2019}

\section{References}

1. DuPaul GJ, Gormley MJ, Laracy SD. Comorbidity of LD and ADHD: implications of DSM-5 for assessment and treatment. J Learn Disabil. 2013; 46(1):43-51. https://doi.org/10.1177/0022219412464351.

2. Willcutt EG, Pennington BF. Comorbidity of reading disability and attentiondeficit/hyperactivity disorder: differences by gender and subtype. J Learn Disabil. 2000;33(2):179-91 Available from: http://csaweb113v.csa.com.proxy. library.vanderbilt.edu/ids70/view_record.php?id=23\&recnum=2\&log=from res\&SID=ch7lj3fcd225laic0oe8027hj0.

3. Pennington BF. From single to multiple deficit models of developmental disorders. Cognition. 2006;101(2):385-413 Available from: http://www.ncbi. $\mathrm{nlm}$.nih.gov/entrez/query.fcgi?cmd=Retrieve\&db=PubMed\&dopt= Citation\&list_uids=16844106.

4. Willcutt E. Behavioral genetic approaches to understand the etiology of comorbidity. Behav Genet Psychopathol. 2014; [cited 2015 Jan 7]; Available from: http://link.springer.com/chapter/10.1007/978-1-4614-9509-3_8.

5. Knopik VS, Neiderhiser JM, DeFries JC, Plomin R. Behavioral genetics. New York: Macmillan Higher Education; 2016

6. Plomin R, Kovas Y. Generalist genes and learning disabilities. Psychol Bull. 2005;131(4):592-617 Available from: http://www.ncbi.nlm.nih.gov/entrez/ query.fcgi? $\mathrm{cm} d=$ Retrieve $\& \mathrm{db}=$ PubMed\&dopt=Citation\&list uids $=16060804$.

7. Willcutt EG, Betjemann RS, Mcgrath LM, Pennington BF. Etiology and neurophysiology of comorbidity between RD and ADHD: The case for multiple deficit models. Cortex. 2011;46(10):1345-61.

8. Catts HW, Gillispie M, Leonard LB, Kail RV, Miller CA. The role of speed of processing, rapid naming, and phonological awareness in reading achievement. J Learn Disabil. 2002;35(6):509-24.

9. Kail R, Hall LK. Processing speed, naming speed, and reading. Dev Psychol. 1994;30(6):949-54. https://doi.org/10.1037/0012-1649.30.6.949.

10. Moll K, Gobel SM, Gooch D, Landerl K, Snowling MJ. Cognitive risk factors for specific learning disorder: processing speed, temporal processing, and working memory. J Learn Disabil. 2016;49(3):272-81. https://doi.org/10.1177/ 0022219414547221.

11. Arnett AB, Pennington BF, Willcutt E, Dmitrieva J, Byrne B, Samuelsson S, et al. A cross-lagged model of the development of ADHD inattention symptoms and rapid naming speed. J Abnorm Child Psychol. 2012;40(8): 1313-26 Cited 2014 Nov 17]; Available from: http://www.pubmedcentral.nih gov/articlerender.fcgi?artid=3546520\&tool=pmcentrez\&rendertype=abstract.

12. Kalff AC, De Sonneville LMJ, Hurks PPM, Hendriksen JGM, Kroes M, Feron FJM, et al. Speed, speed variability, and accuracy of information processing in 5 to 6-year-old children at risk of ADHD. J Int Neuropsychol Soc. 2005: 11(2):173-83.

13. McGrath LM, Pennington BF, Shanahan MA, Santerre-Lemmon LE, Barnard $H D$, Willcutt EG, et al. A multiple deficit model of reading disability and attention-deficit/hyperactivity disorder: searching for shared cognitive deficits. J Child Psychol Psychiatry Allied Discip 2011;52(5):547-557. 2010/12 04. Available from: http://onlinelibrary.wiley.com/store/10.1111/j.1469-7610.2

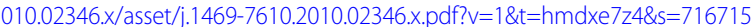
937578985e4785170e6a9475b78c907c3d

14. Peterson RL, Boada R, McGrath LM, Willcutt EG, Olson RK, Pennington BF. Cognitive prediction of reading, math, and attention: shared and unique influences. J Learn Disabil. 2016;49(1):e0119581 Available from: http://ldx. sagepub.com/cgi/doi/10.1177/0022219414521667\%5Cnhttp://www.ncbi.nlm. nih.gov/pubmed/24596111\%5Cnhttp://ldx.sagepub.com/cgi/doi/10.1177/ 0022219414522706\%5Cnhttp://www.ncbi.nlm.nih.gov/pubmed/ 24710743\%5Cnhttp://dx.plos.org/10.1371/journal.pone.011.

15. Shanahan MA, Pennington BF, Yerys BE, Scott A, Boada R, Willcutt EG, et al. Processing speed deficits in attention deficit/hyperactivity disorder and reading disability. J Abnorm Child Psychol. 2006;34(5):585-602 Cited 2013 Oct 22. Available from: http://www.ncbi.nlm.nih.gov/pubmed/16850284.

16. Weiler MD, Bernstein JH, Bellinger D, Waber DP. Information processing deficits in children with attention-deficit/hyperactivity disorder, inattentive type, and children with reading disability. J Learn Disabil. 2002;35(5):448-61 Cited 2013 Oct 25; Available from: http://www.ncbi.nlm.nih.gov/entrez/ query.fcgi?cmd=Retrieve\&db=PubMed\&dopt=Citation\&list_uids=15490541.

17. Willcutt EG, Pennington BF, Olson RK, Chhabildas N, Hulslander J. Neuropsychological analyses of comorbidity between reading disability and attention deficit hyperactivity disorder: in search of the common deficit. Dev Neuropsychol. 2005;27(1):35-78 Available from: http://www.ncbi.nlm. nih.gov/pubmed/15737942.

18. Moura O, Pereira M, Alfaiate C, Fernandes E, Fernandes B, Nogueira S, et al. Neurocognitive functioning in children with developmental dyslexia and attention-deficit/hyperactivity disorder: multiple deficits and diagnostic accuracy. J Clin Exp Neuropsychol. 2017;39(3):296-312. https://doi.org/10. 1080/13803395.2016.1225007.

19. Cheung CHM, Fazier-wood AC, Asherson P, Rijsdijk F, Kuntsi J, Ho C, et al. Shared cognitive impairments and aetiology in ADHD symptoms and reading difficulties. PLoS One. 2014;9(6):e98590 [cited 2014 Jun 13]; Available from: http://www.pubmedcentral.nih.gov/articlerender.fcgi?artid= 4041781\&tool=pmcentrez\&rendertype=abstract.

20. Martinussen R, Hayden J, Hogg-Johnson S, Tannock R. A meta-analysis of working memory impairments in children with attention-deficit/hyperactivity disorder. J Am Acad Child Adolesc Psychiatry. 2005;44(4):377-84.

21. Roodenrys S, Koloski N, Grainger J. Working memory function in attention deficit hyperactivity disordered and reading disabled children. $\mathrm{Br} J \mathrm{Dev}$ Psychol. 2001;19(3):325-37. https://doi.org/10.1348/026151001166128.

22. Rucklidge JJ, Tannock R. Neuropsychological profiles of adolescents with ADHD: effects of reading difficulties and gender. J Child Psychol Psychiatry. 2002;43(8): 988-1003 Available from: http://www.ncbi.n/m.nih.gov/pubmed/12455921.

23. Swanson HL, Mink J, Bocian KM. Cognitive processing deficits in poor readers with symptoms of reading disabilities and ADHD: more alike than different? J Educ Psychol. 1999;91(2):321-33.

24. Tiffin-Richards MC, Hasselhorn M, Woerner W, Rothenberger A, Banaschewski T. Phonological short-term memory and central executive processing in attention-deficit/hyperactivity disorder with/without dyslexia-evidence of cognitive overlap. J Neural Transm. 2008;115(2):227-34 Available from: http://www.ncbi.nlm.nih.gov/pubmed/17906969.

25. de Jong CGW, Van De Voorde S, Roeyers H, Raymaekers R, Oosterlaan J, Sergeant JA. How distinctive are ADHD and RD? Results of a double dissociation study. J Abnorm Child Psychol. 2009;37(7):1007-17. https://doi. org/10.1007/s10802-009-9328-y.

26. Purvis KL, Tannock R. Phonological processing, not inhibitory control, differentiates ADHD and reading disability. J Am Acad Child Adolesc Psychiatry. 2000;39(4):485-94 Cited 2013 Oct 25; Available from: http://www ncbi.nlm.nih.gov/entrez/query.fcgi?cmd=Retrieve\&db=PubMed\&dopt= Citation\&list_uids $=10761351$.

27. Kibby MY, Pavawalla SP, Fancher JB, Naillon AJ, Hynd GW. The relationship between cerebral hemisphere volume and receptive language functioning in dyslexia and attention-deficit hyperactivity disorder (ADHD). J Child Neurol. 2009;24(4):438-48 Cited 2014 Aug 29; Available from: http://www. pubmedcentral.nih.gov/articlerender.fcgi?artid=2664863\&tool= pmcentrez\&rendertype=abstract.

28. Kibby MY, Kroese JM, Krebbs H, Hill CE, Hynd GW. The pars triangularis in dyslexia and ADHD: A comprehensive approach. Brain Lang 2009;111(1):4654. https://doi.org/10.1016/j.bandl.2009.03.001 
29. Goradia DD, Vogel S, Mohl B, Khatib D, Zajac-Benitez C, Rajan U, et al. Distinct differences in striatal dysmorphology between attention deficit hyperactivity disorder boys with and without a comorbid reading disability. Psychiatry Res Neuroimaging. 2016;258(July):30-6.

30. Jagger-Rickels AC, Kibby MY, Constance JM. Global gray matter morphometry differences between children with reading disability, ADHD, and comorbid reading disability/ADHD. Brain Lang. 2018;185(April):54-66. https://doi.org/10.1016/j.bandl.2018.08.004.

31. Langer N, Benjamin C, Becker BLC, Gaab N. Comorbidity of reading disabilities and ADHD: structural and functional brain characteristics. Hum Brain Mapp. 2019. https://doi.org/10.1002/hbm.24552.

32. Norman LJ, Carlisi C, Lukito S, Hart H, Mataix-Cols D, Radua J, et al. Structural and functional brain abnormalities in attention-deficit/hyperactivity disorder and obsessive-compulsive disorder: a comparative meta-analysis. JAMA Psychiatry. 2016;73(8):815-25.

33. Gold AL, Brotman MA, Adleman NE, Lever SN, Steuber ER, Fromm SJ, et al. Comparing brain morphometry across multiple childhood psychiatric disorders. J Am Acad Child Adolesc Psychiatry. 2016;55(12):1027-1037.e3. https://doi.org/10.1016/j.jaac.2016.08.008.

34. Goodkind M, Eickhoff SB, Oathes DJ, Jiang Y, Chang A, Jones-hagata LB, et al. Identification of a common neurobiological substrate for mental illness. JAMA Psychiatry. 2015;5797(4):305-15 Available from: http://www. ncbi.nlm.nih.gov/pubmed/25651064.

35. McGrath LM, Braaten EB, Doty ND, Willoughby BL, Wilson HK, O'Donnell EH, et al. Extending the "cross-disorder" relevance of executive functions to dimensional neuropsychiatric traits in youth. J Child Psychol Psychiatry. 2016;57(4):462-71. https://doi.org/10.1111/jcpp.12463.

36. Snyder HR, Miyake A, Hankin BL. Advancing understanding of executive function impairments and psychopathology: bridging the gap between clinical and cognitive approaches. Front Psychol. 2015;6. https://doi.org/10 3389/fpsyg.2015.00328/abstract.

37. McTeague LM, Goodkind MS, Etkin A. Transdiagnostic impairment of cognitive control in mental illness. J Psychiatr Res. 2016;83:37-46. https:// doi.org/10.1016/j.jpsychires.2016.08.001.

38. Stoodley CJ. Distinct regions of the cerebellum show gray matter decreases in autism, ADHD, and developmental dyslexia. Front Syst Neurosci. 2014;8: 92 Cited 2015 May 14; Available from: http://www.pubmedcentral.nih.gov/ articlerender.fcgi?artid=4033133\&tool=pmcentrez\&rendertype=abstract.

39. Ramus F, Altarelli I, Jednoróg K, Zhao J, Scotto di Covella L. Neuroanatomy of developmental dyslexia: pitfalls and promise. Neurosci Biobehav Rev. 2018;84(July 2017):434-52.

40. Frodl T, Skokauskas N. Meta-analysis of structural MRI studies in children and adults with attention deficit hyperactivity disorder indicates treatment effects. Acta Psychiatr Scand. 2012;125(2):114-26

41. McCarthy $H$, Skokauskas N, Frodl T. Identifying a consistent pattern of neural function in attention deficit hyperactivity disorder: a meta-analysis. Psychol Med. 2014:44(4):869-80.

42. Hoogman M, Bralten J, Hibar DP, Mennes M, Zwiers MP, Schweren LSJ, et al. Subcortical brain volume differences in participants with attention deficit hyperactivity disorder in children and adults: a cross-sectional megaanalysis. Lancet Psychiatry. 2017;4(4):310-9 Available from: http://www.ncbi. nlm.nih.gov/pubmed/28219628.

43. Ashburner J, Friston KJ. Voxel-based morphometry-the methods. Neuroimage. 2000;11(6):805-21.

44. Mechelli A, Price CJ, Friston KJ, Ashburner J. Voxel-based morphometry of the human brain: methods and applications. Curr Med Imaging Rev. 2005;1(2):105-13.

45. Müller VI, Cieslik EC, Laird AR, Fox PT, Radua J, Mataix-Cols D, et al. Ten simple rules for neuroimaging meta-analysis. Neurosci Biobehav Rev. 2018; 84(April 2017):151-61.

46. Moher D, Liberati A, Tetzlaff J, Altman DG, PRISMA Group. Preferred reporting items for systematic reviews and meta-analyses: the PRISMA statement. Ann Intern Med. 2009;151(4):264-9 W64. Available from: http:// www.ncbi.nlm.nih.gov/pubmed/19622511

47. Eckert MA, Berninger WW, Vaden Kl, Gebregziabher M, Tsu L. Gray matter features of reading disability: a combined meta-analytic and direct analysis approach. eNeuro. 2016;3(1). https://doi.org/10.1523/ENEURO.0103-15.2015.

48. Linkersdorfer J, Lonnemann J, Lindberg S, Hasselhorn M, Fiebach CJ. Grey matter alterations co-localize with functional abnormalities in developmental dyslexia: An ALE meta-analysis. PLoS One. 2012;7(8):e43122.

49. Richlan F, Kronbichler M, Wimmer H. Structural abnormalities in the dyslexic brain: a meta-analysis of voxel-based morphometry studies. Hum Brain
Mapp 2013;34(11):3055-3065. Available from: http://www.ncbi.nlm.nih.gov/ pubmed/22711189.

50. Ellison-Wright I, Ellison-Wright Z, Bullmore E. Structural brain change in attention deficit hyperactivity disorder identified by meta-analysis. BMC Psychiatry. 2008:8:1-8.

51. Nakao T, Radua J, Rubia K, Mataix-Cols D. Gray matter volume abnormalities in ADHD: voxel-based meta-analysis exploring the effects of age and stimulant medication. Am J Psychiatry. 2011;168(11):1154-63.

52. Albajara Sáenz A, Villemonteix T, Massat I. Structural and functional neuroimaging in attention-deficit/hyperactivity disorder. Developmental Medicine \& Child Neurology. 2019;61(4):399-405.

53. Collins DL, Zijdenbos AP, Kollokian V, Sled JG, Kabani NJ, Holmes CJ, et al. Design and construction of a realistic digital brain phantom. IEEE Trans Med Imaging. 1998;17(3):463-8.

54. Talairach J, Tournoux P. Co-planar stereotaxic atlas of the human brain: 3dimensional proportional system: an approach to cerebral imaging; 1988.

55. Duan K, Chen J, Calhoun VD, Lin D, Jiang W, Franke B, et al. Neurolmage: clinical neural correlates of cognitive function and symptoms in attentiondeficit / hyperactivity disorder in adults. Neurolmage Clin. 2018; 19(November 2017):374-83. https://doi.org/10.1016/j.nicl.2018.04.035.

56. Pernet $\mathrm{C}$, Andersson J, Paulesu E, Demonet JF. When all hypotheses are right: a multifocal account of dyslexia. Hum Brain Mapp. 2009;30(7):2278-92 Cited 2014 May 30; Available from: http://www.ncbi.n/m.nih.gov/pubmed/19235876.

57. Depue BE, Burgess GC, Bidwell LC, Willcutt EG, Banich MT. Behavioral performance predicts grey matter reductions in the right inferior frontal gyrus in young adults with combined type ADHD. Psychiatry Res Neuroimaging. 2010;182(3):231-7.

58. Maier S, Perlov E, Graf E, Dieter E, Sobanski E, Rump M, et al. Discrete global but no focal gray matter volume reductions in unmedicated adult patients with attention-deficit/hyperactivity disorder. Biol Psychiatry. 2016;80(12):90515. https://doi.org/10.1016/j.biopsych.2015.05.012.

59. Onnink AMH, Zwiers MP, Hoogman M, Mostert JC, Kan CC, Buitelaar J, et al. Brain alterations in adult ADHD: effects of gender, treatment and comorbid depression. Eur Neuropsychopharmacol. 2014;24(3):397-409. https://doi.org/ 10.1016/j.euroneuro.2013.11.011.

60. Seidman LJ, Biederman J, Liang L, Valera EM, Monuteaux MC, Brown A, et al Gray matter alterations in adults with attention-deficit/hyperactivity disorder identified by voxel based morphometry. Biol Psychiatry. 2011;69(9):857-66. https://doi.org/10.1016/j.biopsych.2010.09.053.

61. Saad JF, Gri KR, Kohn MR, Clarke S, Williams LM, Korgaonkar MS. Clinical Regional brain network organization distinguishes the combined and inattentive subtypes of attention deficit hyperactivity disorder. Neurolmage. 2017;15(May):383-90.

62. Amico F, Stauber J, Koutsouleris N, Frodl T. Psychiatry Research: neuroimaging anterior cingulate cortex gray matter abnormalities in adults with attention de fi cit hyperactivity disorder: a voxel-based morphometry study. Psychiatry Res Neuroimaging. 2011;191(1):31-5. https://doi.org/10. 1016/j.pscychresns.2010.08.011

63. Villemonteix T, De Brito SA, Slama H, Kavec M, Balériaux D, Metens T, et al. Grey matter volume differences associated with gender in children with attention-deficit/hyperactivity disorder: a voxel-based morphometry study. Dev Cogn Neurosci. 2015;14:32-7 Available from: http://www.sciencedirect. com/science/article/pii/S1878929315000626.

64. Ahrendts J, Rüsch N, Wilke M, Philipsen A, Eickhoff SB, Glauche V, et al. Visual cortex abnormalities in adults with ADHD: a structural MRI study. World J Biol Psychiatry. 2011;12(4):260-70.

65. Bonath B, Tegelbeckers J, Wilke M, Flechtner H-H, Krauel K. Regional gray matter volume differences between adolescents with ADHD and typically developing controls: further evidence for anterior cingulate involvement. J Atten Disord. 2016. https://doi.org/10.1177/1087054715619682.

66. Bralten J, Greven CU, Franke B, Mennes M, Zwiers MP, Rommelse NNJ, et al. Voxel-based morphometry analysis reveals frontal brain differences in participants with ADHD and their unaffected siblings. J Psychiatry Neurosci. 2016;41(4):272-9.

67. Brieber S, Neufang S, Bruning N, Kamp-Becker I, Remschmidt H, Herpertz-Dahlmann B, et al. Structural brain abnormalities in adolescents with autism spectrum disorder and patients with attention deficit/hyperactivity disorder. J Child Psychol Psychiatry Allied Discip. 2007:48(12):1251-8.

68. Carmona S, Vilarroya O, Bielsa A, Trèmols V, Soliva JC, Rovira M, et al. Global and regional gray matter reductions in ADHD: a voxel-based morphometric study. Neurosci Lett. 2005;389(2):88-93. 
69. He N, Li F, Li Y, Guo L, Chen L, Huang X, et al. Neuroanatomical deficits correlate with executive dysfunction in boys with attention deficit hyperactivity disorder. Neurosci Lett. 2015;600:45-9.

70. lannaccone R, Hauser TU, Ball J, Brandeis D, Walitza S, Brem S. Classifying adolescent attention-deficit/hyperactivity disorder (ADHD) based on functional and structural imaging. Eur Child Adolesc Psychiatry. 2015;24(10): 1279-89. https://doi.org/10.1007/s00787-015-0678-4.

71. Johnston BA, Mwangi B, Matthews K, Coghill D, Konrad K, Steele JD. Brainstem abnormalities in attention deficit hyperactivity disorder support high accuracy individual diagnostic classification. Hum Brain Mapp. 2014; 35(10):5179-89.

72. Kappel V, Lorenz RC, Streifling M, Renneberg B, Lehmkuhl U, Stro A, et al. Effect of brain structure and function on reward anticipation in children and adults with attention deficit hyperactivity disorder combined subtype. 2015;

73. Sutcubasi Kaya B, Metin B, Tas ZC, Buyukaslan A, Soysal A, Hatiloglu D, et al. Gray matter increase in motor cortex in pediatric ADHD: a voxel-based morphometry study. J Atten Disord. 2018;22(7):611-8.

74. Kobel M, Bechtel N, Specht K, Klarhöfer M, Weber P, Scheffler K, et al. Structural and functional imaging approaches in attention deficit/ hyperactivity disorder: does the temporal lobe play a key role? Psychiatry Res Neuroimaging. 2010;183(3):230-6.

75. Kumar U, Arya A, Agarwal V. Neural alterations in ADHD children as indicated by voxel-based cortical thickness and morphometry analysis. Brain Dev. 2017;39(5):403-10. https://doi.org/10.1016/j.braindev.2016.12.002.

76. Lim L, Marquand A, Cubillo AA, Smith AB, Chantiluke K, Simmons A, et al. Disorder-specific predictive classification of adolescents with attention deficit hyperactivity disorder (ADHD) relative to autism using structural magnetic resonance imaging. PLoS One. 2013;8(5):1-10.

77. McAlonan GM, Cheung V, Cheung C, Chua SE, Murphy DGM, Suckling J, et al. Mapping brain structure in attention deficit-hyperactivity disorder: a voxel-based MRI study of regional grey and white matter volume. Psychiatry Res Neuroimaging. 2007;154(2):171-80.

78. Montes LGA, Ricardo-Garcell J, de la Torre LB, Alcántara HP, García RBM, Fernández-Bouzas $A$, et al. Clinical correlations of grey matter reductions in the caudate nucleus of adults with attention deficit hyperactivity disorder. J Psychiatry Neurosci. 2010;35(4):238-46.

79. Moreno-Alcázar A, Ramos-Quiroga JA, Radua J, Salavert J, Palomar G, Bosch R, et al. Brain abnormalities in adults with attention deficit hyperactivity disorder revealed by voxel-based morphometry. Psychiatry Res Neuroimaging. 2016; 254:41-7. https://doi.org/10.1016/j.pscychresns.2016.06.002.

80. Overmeyer S, Bullmore ET, Suckling J, Simmons A, Williams SCR, Santosh PJ, et al. Distributed grey and white matter deficits in hyperkinetic disorder: MRI evidence for anatomical abnormality in an attentional network. Psychol Med. 2001;31(08):1425-35 Available from: http://journals.cambridge.org/ article_S0033291701004706\%5Cnhttp://journals.cambridge.org/action/ displayAbstract?fromPage $=$ online\&aid $=91585 \&$ fileld $=$ S0033291701004706\%5Cnhttp://journals.cambridge.org/action/ displayFulltext?type $=1 \&$ fid $=91586 \&$ jid $=$ PSM\&volumeld $=31$.

81. Roman-Urrestarazu A, Lindholm P, Moilanen I, Kiviniemi V, Miettunen J,

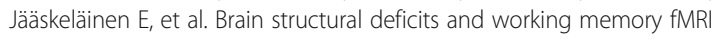
dysfunction in young adults who were diagnosed with ADHD in adolescence. Eur Child Adolesc Psychiatry. 2016;25(5):529-38.

82. Sasayama D, Hayashida A, Yamasue H, Harada Y, Kaneko T, Kasai K, et al. Neuroanatomical correlates of attention-deficit-hyperactivity disorder accounting for comorbid oppositional defiant disorder and conduct disorder. Psychiatry Clin Neurosci. 2010;64(4):394-402.

83. van Wingen GA, van den Brink W, Veltman DJ, Schmaal L, Dom G, Booij J, et al. Reduced striatal brain volumes in non-medicated adult ADHD patients with comorbid cocaine dependence. Drug Alcohol Depend. 2013;131(3):198-203. https://doi.org/10.1016/j.drugalcdep. 2013.05.007.

84. Villemonteix T, De Brito SA, Kavec M, Balériaux D, Metens T, Slama H, et al. Grey matter volumes in treatment naïve vs. chronically treated children with attention deficit/hyperactivity disorder: a combined approach. Eur Neuropsychopharmacol. 2015;25(8):1118-27. https://doi.org/10.1016/j. euroneuro.2015.04.015

85. Yang P, Wang PN, Chuang KH, Jong YJ, Chao TC, Wu MT. Absence of gender effect on children with attention-deficit/hyperactivity disorder as assessed by optimized voxel-based morphometry. Psychiatry Res Neuroimaging. 2008;164(3):245-53. https://doi.org/10.1016/j.pscychresns. 2007.12.013.
86. Brambati SM, Termine C, Ruffino M, Stella G, Fazio F, Cappa SF, et al Regional reductions of gray matter volume in familial dyslexia. Neurology. 2004;63(4):742-5.

87. Brown WE, Eliez S, Menon V, Rumsey JM, White CD, Reiss AL. Preliminary evidence of widespread morphological variations of the brain; 2001. p. 3-5.

88. Eckert MA, Leonard CM, Wilke M, Eckert M, Richards T, Richards A, et al. Anatomical signatures of dyslexia in children: unique information from manual and voxel based morphometry brain measures. Cortex. 2005; 41(3):304-15.

89. Evans TM, Flowers DL, Napoliello EM, Eden GF. Sex-specific gray matter volume differences in females with developmental dyslexia. Brain Struct Funct. 2013;6(8):1041-54.

90. Hoeft F, Meyler A, Hernandez A, Juel C, Taylor-Hill H, Martindale JL, et al. Functional and morphometric brain dissociation between dyslexia and reading ability. Proc Natl Acad Sci. 2007;104(10):4234-9. https://doi.org/10. 1073/pnas.0609399104.

91. Jednoróg K, Marchewka A, Altarelli I, Monzalvo Lopez AK, van ErmingenMarbach M, Grande M, et al. How reliable are gray matter disruptions in specific reading disability across multiple countries and languages? Insights from a large-scale voxel-based morphometry study. Hum Brain Mapp. 2015; 36(5):1741-54. https://doi.org/10.1002/hbm.22734/pdf.

92. Kronbichler M, Wimmer H, Staffen W, Hutzier F, Mair A, Ladurner G. Developmental dyslexia: gray matter abnormalities in the occipitotemporal cortex. Hum Brain Mapp. 2008;29(5):613-25.

93. Liu L, You W, Wang W, Guo X, Peng D, Booth J. Altered brain structure in Chinese dyslexic children. Neuropsychologia. 2013;51(7):1169-76. https://doi. org/10.1016/j.neuropsychologia.2013.03.010.

94. Silani G, Frith U, Demonet JF, Fazio F, Perani D, Price C, et al. Brain abnormalities underlying altered activation in dyslexia: a voxel based morphometry study. Brain. 2005;128(10):2453-61.

95. Siok WT, Niu Z, Jin Z, Perfetti CA, Tan LH. A structural-functional basis for dyslexia in the cortex of Chinese readers. Proc Natl Acad Sci. 2008;105(14): 5561-6. https://doi.org/10.1073/pnas.0801750105.

96. Steinbrink C, Vogt K, Kastrup A, Müller HP, Juengling FD, Kassubek J, et al. The contribution of white and gray matter differences to developmental dyslexia: Insights from DTI and VBM at 3.0 T. Neuropsychologia. 2008;46(13): 3170-8.

97. Tamboer P, Scholte HS, Vorst HCM. Dyslexia and voxel-based morphometry: correlations between five behavioural measures of dyslexia and gray and white matter volumes. Ann Dyslexia. 2015;65(3):121-41.

98. Vinckenbosch E, Robichon F, Eliez S. Gray matter alteration in dyslexia: converging evidence from volumetric and voxel-by-voxel MRI analyses. Neuropsychologia. 2005;43(3):324-31.

99. Xia Z, Hoeft F, Zhang L, Shu H. Neuroanatomical anomalies of dyslexia: disambiguating the effects of disorder, performance, and maturation. Neuropsychologia. 2016;81:68-78. https://doi.org/10.1016/j. neuropsychologia.2015.12.003.

100. Yang YH, Yang Y, Chen BG, Zhang YW, Bi HY. Anomalous cerebellar anatomy in Chinese children with dyslexia. Front Psychol. 2016;7(MAR):1-9.

101. Müller VI, Cieslik EC, Laird AR, Fox PT, Radua J, Mataix-Cols D, et al. Ten simple rules for neuroimaging meta-analysis. Neurosci Biobehav Rev. 2017; 84:151-61.

102. Jednoróg K, Gawron N, Marchewka A, Heim S, Grabowska A. Cognitive subtypes of dyslexia are characterized by distinct patterns of grey matter volume. Brain Struct Funct. 2014;219(5):1697-707.

103. Krafnick AJ, Flowers DL, Luetje MM, Napoliello EM, Eden GF. An investigation into the origin of anatomical differences in dyslexia. J Neurosci. 2014;34(3):901-8 Cited 2014 Aug 25; Available from: http://www. pubmedcentral.nih.gov/articlerender.fcgi?artid=3891966\&tool= pmcentrez\&rendertype=abstract.

104. Evans TM, Flowers DL, Napoliello EM, Eden GF. Sex-specific gray matter volume differences in females with developmental dyslexia. Brain Struct Funct. 2014;219(3):1041-54.

105. Turkeltaub PE, Eden GF, Jones KM, Zeffiro TA. Meta-analysis of the functional neuroanatomy of single-word reading: method and validation. Neuroimage. 2002;16(3):765-80 Cited 2014 May 25; Available from: http://linkinghub. elsevier.com/retrieve/pii/S1053811902911316.

106. Eickhoff SB, Laird AR, Grefkes C, Wang LE, Zilles K, Fox PT. Coordinate-based activation likelihood estimation meta-analysis of neuroimaging data: a random-effects approach based on empirical estimates of spatial uncertainty. Hum Brain Mapp. 2009;30(9):2907-26. 
107. Eickhoff SB, Bzdok D, Laird AR, Kurth F, Fox PT. Activation likelihood estimation meta-analysis revisited. Neuroimage. 2012;59(3):2349-61. https:// doi.org/10.1016/j.neuroimage.2011.09.017.

108. Turkeltaub PE, Eickhoff SB, Laird AR, Fox M, Wiener M, Fox P. Minimizing within-experiment and within-group effects in activation likelihood estimation meta-analyses. Hum Brain Mapp. 2012:33(1):1-13.

109. Lancaster JL, Tordesillas-Gutiérrez D, Martinez M, Salinas F, Evans A, Zilles K, et al. Bias between MNI and Talairach coordinates analyzed using the ICBM152 brain template. Hum Brain Mapp. 2007;28(11):1194-205.

110. Fox KCR, Spreng RN, Ellamil M, Andrews-Hanna JR, Christoff K. The wandering brain: meta-analysis of functional neuroimaging studies of mindwandering and related spontaneous thought processes. Neuroimage. 2015; 111:611-21.

111. Castellanos FX. Toward a pathophysiology of attention-deficit/hyperactivint disorder. Clin Pediatr (Phila). 1997;36(7):381-93

112. Hancock R, Richlan F, Hoeft F. Possible roles for fronto-striatal circuits in reading disorder. Neurosci Biobehav Rev. 2017;72:243-60. https://doi.org/10. 1016/j.neubiorev.2016.10.025.

113. Maisog JM, Einbinder ER, Flowers DL, Turkeltaub PE, Eden GF. A metaanalysis of functional neuroimaging studies of dyslexia. Ann N Y Acad Sci. 2008;1145:237-59 Cited 2015 Jan 4; Available from: http://www.ncbi.nlm.nih. gov/pubmed/19076401.

114. Richlan F, Kronbichler M, Wimmer H. Functional abnormalities in the dyslexic brain: A quantitative meta-analysis of neuroimaging studies. Hum Brain Mapp. 2009;30(10):3299-308.

115. Richlan F, Kronbichler M, Wimmer H. Meta-analyzing brain dysfunctions in dyslexic children and adults. Neuroimage. 2011;56(3):1735-42.

116. Ullman MT, Pullman MY. A compensatory role for declarative memory in neurodevelopmental disorders. Neurosci Biobehav Rev. 2015;51:205-22. https://doi.org/10.1016/j.neubiorev.2015.01.008

117. Krishnan S, Watkins KE, Bishop DVM. Neurobiological basis of language learning difficulties. Trends Cogn Sci. 2016;20(9):701-14 Available from: http://jslhr.pubs.asha.org/article.aspx?doi=10.1044/2015_JSLHR-L-14-0324.

118. Lum JAG, Ullman MT, Conti-Ramsden G. Procedural learning is impaired in dyslexia: evidence from a meta-analysis of serial reaction time studies. Res Dev Disabil. 2013;34(10):3460-76. https://doi.org/10.1016/j.ridd.2013.07.017.

119. Barnes KA, Howard JH Jr, Howard DV, Kenealy L, Vaidya CJ. Two forms of implicit learning in childhood ADHD. Dev Neuropsychol. 2010;35(5):494-505.

120. Laasonen M, Väre J, Oksanen-Hennah H, Leppämäki S, Tani P, Harno H, et al. Project DyAdd: implicit learning in adult dyslexia and ADHD. Ann Dyslexia. 2014;64(1):1-33. https://doi.org/10.1016/j.bandc.2012.08.002.

121. Curtis CE, D'Esposito M. Persistent activity in the prefrontal cortex during working memory. Trends Cogn Sci. 2003;7(9):415-23.

122. Ridderinkhof KR, Ullsperger M, Crone EA, Nieuwenhuis S. The role of the medial frontal cortex in cognitive control. Science. 2004;306(5695):443-7.

123. Cañas A, Juncadella M, Lau R, Gabarrós A, Hernández M. Working memory deficits after lesions involving the supplementary motor area. Front Psychol. 2018:9:765.

124. Selzam S, Dale PS, Wagner RK, DeFries JC, Cederlöf M, O'Reilly PF, et al. Genome-wide polygenic scores predict reading performance throughout the school years. Sci Stud Read. 2017;21(4):334-49. https://doi.org/10.1080/ 10888438.2017.1299152.

125. Demontis D, Walters RK, Martin J, Mattheisen M, Als TD, Agerbo E, et al. Discovery of the first genome-wide significant risk loci for ADHD. 2017

126. Turken A, Whitfield-Gabrieli S, Bammer R, Baldo JV, Dronkers NF, Gabrieli JDE. Cognitive processing speed and the structure of white matter pathways: convergent evidence from normal variation and lesion studies. Neuroimage. 2008;42(2):1032-44 Cited 2013 Nov 16. Available from: http:// www.pubmedcentral.nih.gov/articlerender.fcgi?artid=2630965\&tool= pmcentrez\&rendertype=abstract.

127. Hudziak JJ, Achenbach TM, Althoff RR, Pine DS. A dimensional approach to developmental psychopathology. Int J Methods Psychiatr Res. 2007; 16(S1):S16-23

128. Plomin R, Haworth CM, Davis OS. Common disorders are quantitative traits. Nat Rev Genet. 2009;10(12):872-8 2009/10/28. Available from: http://www. ncbi.nlm.nih.gov/entrez/query.fcgi?cmd=Retrieve\&db=PubMed\&dopt= Citation\&list_uids=19859063.

129. Acar F, Seurinck R, Eickhoff SB, Moerkerke B. Assessing robustness against potential publication bias in activation likelihood estimation (ALE) metaanalyses for fMRI. PLoS One. 2018;13(11):1-23.
130. Samartsidis P, Montagna S, Laird AR, Fox PT, Johnson TD, Nichols TE. Estimating the number of missing experiments in a neuroimaging metaanalysis. bioRxiv. 2017:225425 Available from: https://www.biorxiv.org/ content/early/2017/11/27/225425.

131. Ioannidis JPA. Excess significance bias in the literature on brain volume abnormalities. Arch Gen Psychiatry. 2011;68(8):773-80.

132. Jennings RG, Van Horn JD. Publication bias in neuroimaging research: implications for meta-analyses. Neuroinformatics. 2012;10(1):67-80.

133. David SP, Ware JJ, Chu IM, Loftus PD, Fusar-Poli P, Radua J, et al. Potential reporting bias in fMRI studies of the brain. PLoS One. 2013;8(7):e70104.

134. Ioannidis JPA. Why most published research findings are false. PLoS Med. 2005;2(8):e124 Cited 2013 Oct 17. Available from: http://www. pubmedcentral.nih.gov/articlerender.fcgi?artid=1182327\&tool= pmcentrez\&rendertype=abstract.

\section{Publisher's Note}

Springer Nature remains neutral with regard to jurisdictional claims in published maps and institutional affiliations.
Ready to submit your research? Choose BMC and benefit from:

- fast, convenient online submission

- thorough peer review by experienced researchers in your field

- rapid publication on acceptance

- support for research data, including large and complex data types

- gold Open Access which fosters wider collaboration and increased citations

- maximum visibility for your research: over $100 \mathrm{M}$ website views per year

At $\mathrm{BMC}$, research is always in progress.

Learn more biomedcentral.com/submissions 